\title{
Role of the PD-1/PD-L1 Signaling in Multiple Sclerosis and Experimental Autoimmune Encephalomyelitis: Recent Insights and Future Directions
}

\author{
Yan $\mathrm{Mi}^{1} \cdot$ Jinming $\operatorname{Han}^{1,2} \cdot \operatorname{Jie} \mathrm{Zhu}^{1,3} \cdot \operatorname{Tao}^{\operatorname{Jin}^{1}}{ }^{1}$
}

Received: 17 March 2021 / Accepted: 12 July 2021 / Published online: 3 September 2021

(c) The Author(s) 2021

\begin{abstract}
Multiple sclerosis (MS) is an autoimmunity-related chronic demyelination disease of the central nervous system (CNS), causing young disability. Currently, highly specific immunotherapies for MS are still lacking. Programmed cell death 1 (PD-1) is an immunosuppressive co-stimulatory molecule, which is expressed on activated T lymphocytes, B lymphocytes, natural killer cells, and other immune cells. PD-L1, the ligand of PD-1, is expressed on T lymphocytes, B lymphocytes, dendritic cells, and macrophages. PD-1/PD-L1 delivers negative regulatory signals to immune cells, maintaining immune tolerance and inhibiting autoimmunity. This review comprehensively summarizes current insights into the role of PD-1/PD-L1 signaling in MS and its animal model experimental autoimmune encephalomyelitis (EAE). The potentiality of PD-1/PD-L1 as biomarkers or therapeutic targets for MS will also be discussed.
\end{abstract}

Keywords PD-1 PD-L1 · Multiple sclerosis · Experimental autoimmune encephalomyelitis · Immune tolerance

\section{Introduction}

Multiple sclerosis (MS) is a demyelinating disease of the central nervous system (CNS), attacking myelinated axons and leading to progressive physical disability. Genetic predisposition, epigenetic factors, lifestyle, and environmental factors all contribute to the risk of MS [1]. Previous studies indicated the immune dysfunction playing a primary role

Tao Jin

drtao.jin@hotmail.com; jin_tao@jlu.edu.cn

Yan Mi

miyanjlu@163.com

Jinming Han

hanjinming1202@126.com

Jie Zhu

jzhuhs@yahoo.com; jie.zhu@ki.se

1 Department of Neurology and Neuroscience Center, The First Hospital of Jilin University, Xinmin Street 71\#, Changchun 130021, China

2 Present Address: Department of Neurology, Xuanwu Hospital, Capital Medical University, Beijing, China

3 Department of Neurobiology, Care Sciences and Society, Karolinska Institutet, Karolinska University Hospital, Solna, Stockholm, Sweden in the pathogenesis of MS [2-4]. Various types of immune cells including $\mathrm{T}$ cells, B cells, natural killer (NK) cells, dendritic cells (DCs), and macrophages/microglia are involved in the disease course [5]. Therefore, the modulation of immune response has drawn great attention recently. Several disease-modifying therapies (DMTs) have been discovered and approved to treat MS by targeting the immune system [6]. Non-specific therapeutic approaches may cause serious adverse events, such as leukemia and leukopenia [7]. Although the clinical development of DMTs has made encouraging success, there is still a remaining unmet need of highly specific treatment for MS [8].

Over the past years, a growing body of studies have suggested the crucial role of programmed cell death 1 (PD-1) and its ligand PD-L1 in maintaining immune tolerance and preventing autoimmunity. The involvement of PD-1/PD-L1 in MS has aroused increasing attention. In this review we first outline the cell-based immunomodulation of PD-1/ PD-L1 signaling pathway. We then discuss current insight into the role of PD-1/PD-L1 in MS and its animal model experimental autoimmune encephalomyelitis (EAE) and summarize the regulation of PD-1/PD-L1 expression. In addition, the potentiality of PD-1/PD-L1 as biomarkers or therapeutic targets for MS and future directions of research will be introduced. 


\section{PD-1 Receptor and Its Ligands}

PD-1 (encoded by $P d c d 1$ gene), also known as CD279, is an immunosuppressive co-receptor belonging to the $\mathrm{CD} 28$ family, mainly expressed on T lymphocytes, B lymphocytes and other immune cells [9]. The extracellular region of PD-1 is a single immunoglobulin variable-like domain and its cytoplasmic region contains an immunoreceptor tyrosine-based inhibitory motif (ITIM) and an immunoreceptor tyrosine-based switch motif (ITSM) [10]. Upon T-cell receptor (TCR) stimulation, the tyrosine residues of ITIM and ITSM are phosphorylated, recruiting src homology 2-domain-containing tyrosine phosphatase 1 (SHP1)

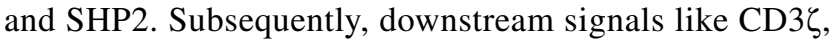
Zeta-chain-associated protein kinase 70 (ZAP-70) and protein kinase $\mathrm{C}-\theta$ (PKC- $\theta$ ) are dephosphorylated, resulting in the inhibition of TCR-mediated responses [11]. As for B cells, PD-1 mediates the dephosphorylation of $\operatorname{Ig} \beta$, Syk, phospholipase C- $\gamma 2$ (PLC- $\gamma 2$ ) and extracellular signal-regulated kinase (ERK). These effects are dependent on the recruitment of SHP2 to the ITSM tyrosine [12].

PD-L1 (CD274, B7-H1) and PD-L2 (CD273, B7-DC) are the ligands of PD-1, belonging to the $\mathrm{B} 7$ family [13]. The two ligands share $40 \%$ identical amino acids [14]. The binding of PD-L2/PD-1 exhibits 2-six fold higher affinity than PD-L1/PD-1 interactions [15]. Although the binding affinity of PD-L2/PD-1 is high, relatively low expression of PD-L2 causes the interactions of PD-L1/PD-1 more competitive than PD-L2/PD-1. These diverse properties of PD-L1 and PD-L2 may contribute to the discrepancy of their involvement in PD-1 signal. PD-L1 is expressed on $\mathrm{T}$ cells and antigen-presenting cells (APCs) including B cells, DCs, monocytes and macrophages. PD-L1 can also be expressed on parenchymal tissues including vascular endothelial cells and pancreatic islet cells [16]. In contrast, PD-L2 is expressed on a few types of non-lymphoid cells, DCs and monocytes [17]. Different expression patterns of two ligands suggest a more important role of PD-L1 for tissue tolerance. The two ligands exhibited different functional features since PD-L1 is slightly more effective than PD-L2 on inhibiting the activation of T cells [18]. In support of this, a recent study demonstrated that the immunosuppressive role of PD-L2 in anti-tumor immunity is less significant than that of PD-L1 [19]. The role of PD-L1 and PD-L2 in modulating invariant natural killer T (iNKT)cell-mediated airway hyperreactivity (AHR) in allergic asthma is unexpectedly opposite, which may be caused by distinct cytokine production [20]. In the graft versus host disease (GvHD)-like model, PD-1 was involved in the proliferation of alloreactive T cells via PD-1/PD-L2 pathway [21]. In some types of autoimmune models, PD-1/ PD-L1, but not PD-1/PD-L2 interactions, has a crucial role in regulating T-cell functions, affecting the severity of the diseases [22-24]. However, some studies demonstrated that both PD-L1 and PD-L2 have the capacity for limiting autoimmunity [25, 26]. PD-L2 was able to exert its function through a receptor other than PD-1 [27]. We are just beginning to understand functional differences between PD-L1 and PD-L2. Owing to the growing insights into the role of PD-1/PD-L1 interactions in immune tolerance and translational therapies for autoimmunity, we put an emphasis on the immune modulation of PD-1/PD-L1 in this review.

\section{Application of PD-1/PD-L1 as an Immunotherapy for Cancer and Autoimmune Diseases}

The expression of PD-L1 can be significantly upregulated on many malignant cell types, which is capable of constraining anti-tumor T-cell responses [28, 29]. Taken together with the discovery that PD-1 signaling induces T-cell dysfunction, PD-1/PD-L1 axis has been considered a promising strategy for breaking the tumor escape [30]. Both preclinical and clinical studies proved that blockade of PD-1 or PD-L1 inhibits tumor growth or delay progression in a broad spectrum of tumor types including solid and hematologic malignancies [31-35]. The Food and Drug Administration (FDA) approved anti-PD-1 antibody nivolumab as the first PD-1-targeting immune checkpoint blockade therapy for melanoma in 2014 [36]. In 2016, atezolizumab became the first FDA-approval PD-L1 inhibitor for treating urothelial carcinoma [36]. Currently, more than 5 PD-1/PD-L1 blockade therapies have been approved for the treatment of tumors [30]. Due to the complexity of immunomodulatory network and the heterogeneity of neoplasms and hosts, combinatorial regimens with PD-1/PD-L1 pathway blockade are just unfolding. PD-L1 expression has been demonstrated to be correlated to clinical response after PD-1-based therapy $[37,38]$. Making use of potential predictive biomarkers is instructive to guide the rational application of the immune checkpoint blockade.

PD-1/PD-L1 not only occupies an important position in cancer immunotherapy, but also attracts much attention in the field of autoimmunity. Two decades ago, the deficiency of PD-1 was observed to cause lupus-like IgG3 deposition glomerulonephritis and destructive arthritis in mice [39]. Plenty of studies confirmed the engagement of PD-1 in the pathogenesis of autoimmune diseases [40-42]. The immune regulation of PD-1 is strain-specific [9]. For example, gene polymorphisms in $P d c d l$ are associated with the susceptibility of autoimmune diseases including rheumatoid arthritis (RA), type 1 diabetes mellitus (T1DM), systemic lupus erythematosus (SLE), ankylosing spondylitis (AS) and MS 
[43-47]. Similarly, PD-L1 deletion can promote autoimmunity [23, 48]. Certain autoimmune diseases may occur in cancer patients who are treated with anti-PD-1 or antiPD-L1 antibodies [49, 50]. All these facts hint therapeutic potential to upregulate the PD-1/PD-L1 pathway for autoimmune diseases. Transgenic nonobese diabetic (NOD) mice over-expressing PD-L1 on islet cells significantly decreased the incidence of both spontaneous and lymphocyte transfermediated diabetes [51]. However, another study inferred an opposite conclusion that transgenic PD-L1 expression on the pancreatic islets promoted T cell-dependent spontaneous autoimmune diabetes and transplant rejection [52]. Her et al. detected the plasma concentrations of soluble PD-L1 in SLE, RA patients and healthy controls. Their results demonstrated that there were no significant differences among groups [53]. While the synovium and synovial fluid of RA was abundant in PD- ${ }^{+} \mathrm{T}$ cells and PD-L1 ${ }^{+}$macrophages [54], the expression of PD- 1 on $\mathrm{T}$ cells had a positive correlation with the disease activity [55]. We propose that elevated expression of PD-1 may serve as a negative feedback on the breakdown of peripheral immune tolerance. Encouragingly, PD-1 activation induced by PD-L1-Fc fusion protein in vitro suppressed $\mathrm{T}$-cell proliferation and decreased the production of interferon gamma (IFN- $\gamma$ ) from $\mathrm{T}$ cells in RA patients. Soluble PD-L1Ig treatment ameliorated the severity of collagen-induced arthritis (CIA) mice [54]. Stimulated PD-1 with PD-L1Ig fusion protein in experimental autoimmune glomerulonephritis (EAG) showed a marked reduction in corresponding parameters including albuminuria, serum creatinine, serum urea, segmental necrosis and tubular damage [56]. PD-L1Ig treatment resulted in low autoantibody production, delayed disease progression and prolonged survival in SLE murine model [57]. Experimental autoimmune neuritis (EAN) is an animal model of Guillain-Barré syndrome (GBS) with reactive $\mathrm{T}$ cells and macrophages accumulating in the peripheral nervous system. Intraperitoneal administration of PD-L1 attenuated disease severity by inhibiting inflammatory infiltration, demyelination and deficits of peripheral nerves in both preventative and therapeutic groups of EAN rats [58]. In summary, PD-1/PD-L1 may serve as a therapeutic target for autoimmune diseases.

\section{Association Between PD-1/PD-L1 and Immune Cells in MS/EAE}

MS can be classified into relapsing-remitting MS (RRMS), primary progressive MS (PPMS), and secondary progressive MS (SPMS) [59]. The pathological hallmark of MS is focal demyelinating lesions in the CNS, including breakdown of the blood-brain barrier (BBB), immune cell infiltration, demyelination, oligodendrocyte loss, gliosis, axonal or neuronal degeneration [60]. Despite complex underlying mechanisms of MS remain incompletely understood, it is generally accepted that MS is triggered by autoimmune response toward CNS self-antigens. Immune dysregulation is thought to be crucial for the occurrence and development of MS. Inflammation is evident during different disease stages of MS, involving both innate and adaptive immunemediated mechanisms. During acute phase DCs, macrophages, $\mathrm{T}$ cells and $\mathrm{B}$ cells from the periphery infiltrate across the BBB. They produce proinflammatory cytokines, chemokines and molecules to impair the myelin sheath. By contrast, during chronic phase diffuse inflammatory cells are infiltrated and CNS-resident microglia are chronically activated, resulting in constantly axonal injury, neuron loss, and pronounced atrophy of the gray and white matter [61]. Ultimately, neuroinflammation can be decreased and confined to the CNS compartments during disease progression. Therefore, peripheral immune cells and CNS-resident innate immune cells are key contributors of MS pathology at early and progressive stages, respectively. The former is the main target of current DMTs (summarized in Table 1).

Taken together, T cells, B cells, NK cells, DCs, and microglia/macrophages are actively involved in the pathogenesis of MS. Detailed roles of each immune cell in MS pathogenesis are complicated, which may depend on the disease stage and microenvironment. Precise functional regulation of these immune cells is thus of uttermost importance in potential therapeutic development for MS. A growing number of evidence has shown that PD-1/PD-L1 signaling exerts complex regulatory impacts on immune responses. Here we discuss the moderating role and potential mechanisms of PD-1/PD-L1 signaling in various immune cells during MS/ EAE.

\section{T Lymphocytes}

$\mathrm{T}$ lymphocytes are critical in adaptive immune responses, modifying the balance between protective immunity and tolerance. The autoimmunity of EAE is mainly mediated by effector T cells, suggesting a key role of antigen-specific $\mathrm{T}$ cells in MS/EAE. Specifically, Th1, Th17 cells and CD8 ${ }^{+}$ $\mathrm{T}$ cells are pathogenic in MS/EAE, while regulatory $\mathrm{T}$ cells (Tregs) and Th2 cells suppress autoimmune responses [61]. In MS/EAE, central and peripheral tolerance of $\mathrm{T}$ cells can be broken through defective functions of Tregs and/ or impaired immunosuppressive modulation of effector $\mathrm{T}$ cells. The autoreactive T cells that target CNS antigens can be activated in the periphery and then differentiated into $\mathrm{CD}^{+}{ }^{+} \mathrm{Th} 1, \mathrm{Th} 17$ cells, and $\mathrm{CD} 8^{+} \mathrm{T}$ cells. These effector $\mathrm{T}$ cells are infiltrated and re-activated in the CNS, causing neuroinflammation.

PD-1 and PD-L1 are involved in central tolerance mechanisms of $\mathrm{T}$ cells. The goal of central tolerance is to delete self-reactive clones during negative selection of $\mathrm{T}$ cell 


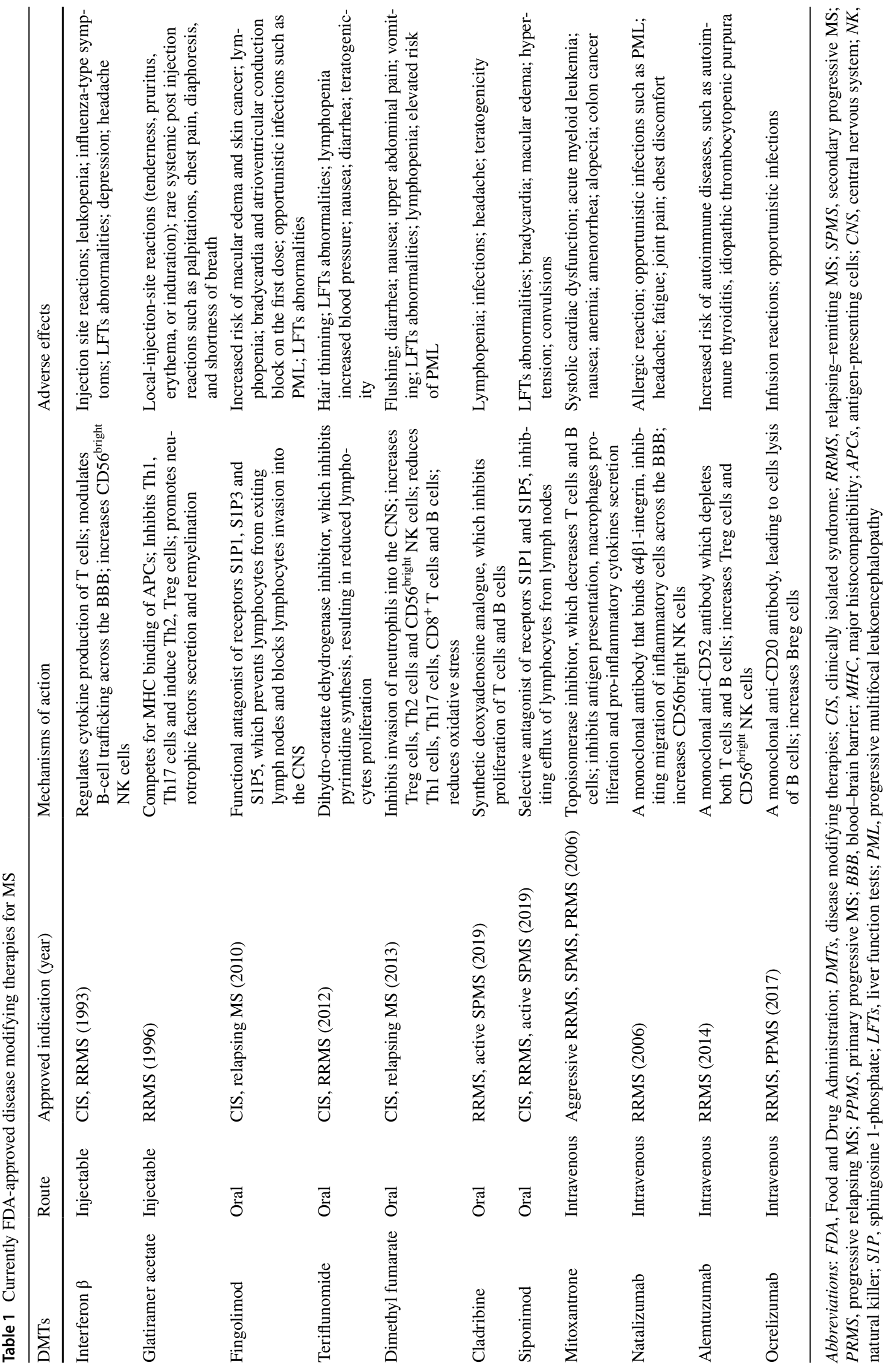




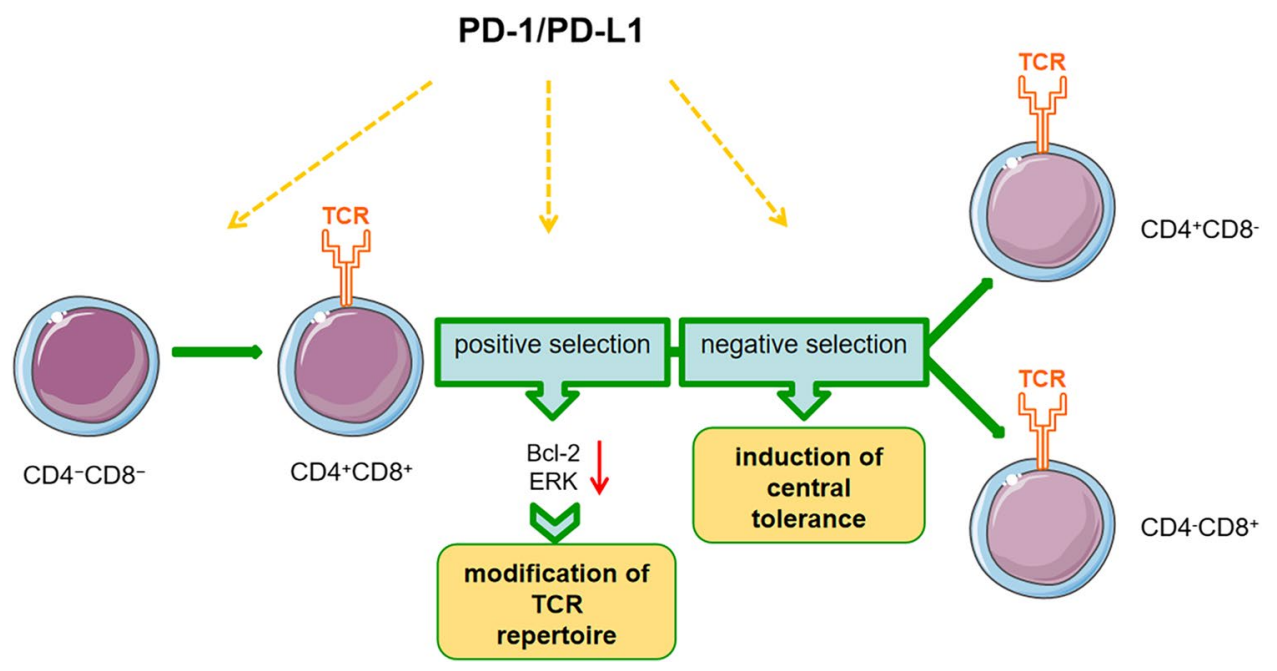

Fig. 1 PD-1/PD-L1 regulates T cell development. PD-1 and PD-L1 are involved in $\mathrm{T}$ cell development in the thymus. PD-1 is expressed on $\mathrm{CD}^{-} \mathrm{CD}^{-}$double-negative thymocytes and $\mathrm{PD}-\mathrm{L} 1$ is widely expressed in the thymic cortex. PD-1 modulates TCR development and thymocyte transition to the $\mathrm{CD} 4^{+} \mathrm{CD} 8^{+}$double positive cells. PD-1 signaling regulates the TCR repertoire by controlling TCR signaling thresholds during positive selection. Loss of PD-L1 signaling at this stage results in a high number of double positive $\mathrm{T}$ cells.

development, thus avoiding autoimmunity. PD-1/PD-L1 interactions contribute to $\mathrm{T}$ cell development (Fig. 1). The expression of PD- 1 can be noted in $\mathrm{CD}^{-}{ }^{-} \mathrm{CD} 8^{-}$double-negative (DN) thymocytes, and PD-L1 is widely expressed in the thymic cortex. PD-1 deficiency promoted thymocyte transition from $\mathrm{DN}$ to $\mathrm{CD} 4^{+} \mathrm{CD} 8^{+}$double positive (DP) thymocytes and decreased the efficiency of positive selection [62]. PD-1 may regulate the TCR repertoire of mature T lymphocytes by controlling TCR signaling thresholds. In addition, transgenic mice that constitutively overexpressed PD-1 on $\mathrm{CD} 4^{+} \mathrm{CD} 8^{+}$thymocytes displayed defects in positive selection and thymocyte maturation, which can be resolved upon the elimination of PD-L1 [63]. PD-L1-deficient mice had great numbers of DP and $\mathrm{CD}^{+}$thymocytes, indicating that PD-L1 is also involved in regular thymic selection. Further mechanistic experiments showed that TCR/PD-1 cocrosslinking inhibited B-cell lymphoma-2 (Bcl-2) upregulation and extracellular signal-regulated kinase (ERK) phosphorylation, both of which are downstream of TCR signaling playing a role in thymocyte development. Moreover, $P d c d 1$ contributes to the modulation of negative selection at the DP stage and has been identified as a candidate gene of defective central tolerance in NOD mice $[64,65]$. So far, how PD-1 and PD-L1 regulate thymic selection and modulate TCR signaling thresholds are poorly defined.

$\mathrm{T}$ cell activation requires both antigen-specific signals from peptide-MHC complexes and antigen-independent signals from co-signaling molecules. Two sets of co-signaling molecules are cell-surface molecules that transduce
TCR/PD-1 cocross-linking inhibits Bcl-2 upregulation and ERK phosphorylation. Both of them are downstream of TCR signaling and are essential for thymocyte development. PD-1/PD-L1 also plays a role in negative selection, contributing to the induction of central tolerance. Abbreviations: PD-1, programmed cell death 1; PD-L1, programmed cell death 1 ligand 1; TCR, T-cell receptor; Bcl-2, B-cell lymphoma-2; ERK, extracellular signal-regulated kinase

signals into T cells to modulate TCR signaling positively (co-stimulatory molecules, such as CD28) or negatively (co-inhibitory molecules) [66]. As described before, PD-1 primarily transmit a co-inhibitory signal through the tyrosine phosphatase SHP1 and SHP2 to enfeeble T-cell activation when engaged with PD-L1 [11]. In other words, PD-1/ PD-L1 paralyzes T cells in a hyporesponsive state called "anergy," which is responsible for peripheral tolerance and immune homeostasis (Fig. 2). In the condition of chronic viral infection, $\mathrm{T}$ cell exhaustion is maintained in order to avoid severe disease, while the administration of PD-1/ PD-L1 antibodies enhances T cell motility and restores T cell ability to lyse target cells and secrete proinflammatory cytokines such as IFN- $\gamma$, causing fatal diseases [67, 68]. In autoimmune diseases, the upregulation of PD-1 signaling on $\mathrm{T}$ cells promoted the resolution of inflammation and ameliorated disease severity by inducing the anergic state of $\mathrm{T}$ cells and controlling $\mathrm{T}$ cell responses [54, 69]. PD-1-mediated decreased phosphorylation of TCR signaling molecules including ZAP-70, PKC- $\theta$, CD3 $\zeta$, Vav1, PLC $\gamma 1$ and further downstream molecules including c-Jun N-terminal kinase (JNK), retrovirus-associated DNA sequences (RAS), extracellular signal-regulated kinase kinase (MEK) and ERK [11, 68, 70, 71]. Apart from TCR signaling, co-stimulatory molecules CD28 and inducible T-cell co-stimulator protein (ICOS) are also reported to be the target signalings of PD-1/ PD-L1 [72] Tyrosine phosphorylation of CD28 recruits and activates phosphatidylinositol 3-kinase (PI3K), resulting in serine-threonine kinase AKT phosphorylation. PI3K-AKT 


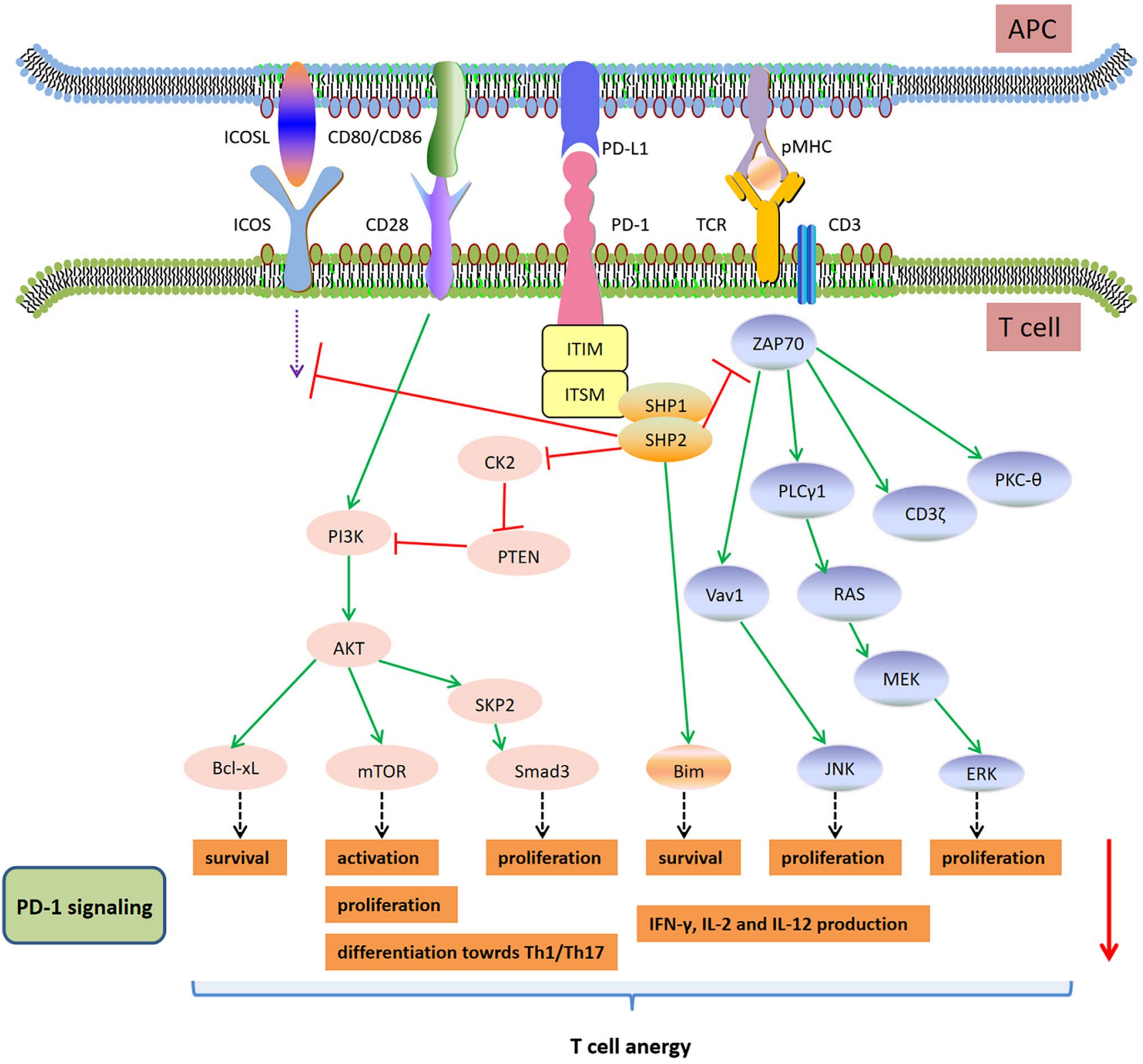

activation facilitates enhanced glucose uptake, glycolysis and cellular metabolism of $\mathrm{T}$ cells, which can be restrained through PD-1 engagement [10]. It is implied that the inhibition of the PI3K-AKT pathway through PD-1 involves phosphatase and tensin homolog (PTEN) dephosphorylation, mediated by casein kinase 2 (CK2) downregulation [73]. A recent study demostrated that $\mathrm{CD} 28$ is a primary target of PD-1-mediated inhibition, which has yielded significant insight into the signaling pathways affected by PD-1 activation [74]. The fluorescence resonance energy transfer (FRET)-based assay indicated that SHP2, but not SHP1, is the major effector of PD-1. SHP2 recruitment requires Lck-mediated dual phosphorylation of PD-1. Notably, PD1-SHP2 displays preferential dephosphorylation of CD28, rather than TCR. Nevertheless, data in vitro revealed that enhanced CD28 signal can overcome PD-1-induced inhibition by augmenting interleukin-2 (IL-2) production in the presence of anti-CD3/CD86, which implies relatively low susceptibility of CD28 signal to PD-1-mediated negative regulation $[72,75]$. The contradictions of these findings may be attributed to complicated dependence of diverse $\mathrm{T}$ cell states on TCR and CD28 signals. Interestingly, SHP2 is dispensable for PD-1 signaling and the induction of T-cell exhaustion in vivo [76]. Therefore, there is a degree of redundancy in downstream signalings of PD-1. Specific effects of PD-1 on related intracellular signaling pathways in diverse $\mathrm{T}$ cell states (naïve, effector, memory, anergic or exhausted T cells) need further investigation.

In 2002, Laura L and colleagues firstly discovered that PD-L1/PD-1 interactions suppress CD3-mediated T cell 
४Fig. 2 PD-1 signaling enfeebles $T$ cell functions. When engaged with PD-L1, PD-1 transmits a co-inhibitory signal to hinder T cell activation through the phosphorylation of ITIM and ITSM, thereby recruiting the tyrosine phosphatase SHP1 and SHP2. PD-1 then mediates decreased phosphorylation of TCR signaling transducers including ZAP-70, PKC- $\theta$, CD3 $\zeta$, Vav1, PLC $\gamma 1$, and further downstream molecules JNK, RAS, MEK, and ERK. In addition to TCR signaling, PD-1 can also hamper co-stimulatory molecules CD28 and ICOS. Tyrosine phosphorylation of CD28 recruits and activates $\mathrm{PI} 3 \mathrm{~K}$, resulting in AKT phosphorylation. PI3K-AKT activation facilitates enhanced glucose uptake, glycolysis and cellular metabolism of $\mathrm{T}$ cells, which can be restrained through PD-1 engagement. The inhibition of the PI3K-AKT pathway through PD-1 involves PTEN dephosphorylation, mediated by CK2 downregulation. PD-1 blocks cell cycle progression through the G1 phase by inhibiting SKP2 expression and Smad3 activation, which is mediated by PI3K-AKT, RAS and MEK-ERK pathways, leading to the downregulation of glycolytic enzyme activity and decreased T cell expansion. PD-1 signaling alters $\mathrm{T}$ cell differentiation by decreasing Th1 cells and Th17 cells as well as increasing Th2 cells and Tregs, which induced by the PI3K-AKT-mTOR pathway. During T cell activation, CD28 stimulation retains $\mathrm{T}$ cell survival by upregulating the expression of antiapoptotic gene $B c l-x L$. PD-1 ligation hampers Bcl-xL expression by limiting PI3K activation. PD-L1 can enhance the death of effector $\mathrm{CD}^{+} \mathrm{T}$ cells through the upregulation of pro-apoptotic molecule $\mathrm{Bim}$, causing the depletion of memory $\mathrm{CD}^{+} \mathrm{T}$ cells. Meanwhile, PD-1 signaling alters cytokine production of $\mathrm{T}$ cells by attenuating proinflammatory cytokine (IFN- $\gamma$, IL-2 and IL-12) production and increasing anti-inflammatory cytokine IL-10 secretion. Abbreviations: $\mathrm{PD}-1$, programmed cell death 1 ; PD-L1, programmed cell death 1 ligand 1; APC, antigen-presenting cell; TCR, T-cell receptor; ICOS, inducible T-cell co-stimulator protein; ICOSL, inducible T-cell co-stimulator ligand; ITIM, immunoreceptor tyrosine-based inhibitory motif; ITSM, immunoreceptor tyrosine-based switch motif; SHP, src homology 2-domain-containing tyrosine phosphatase; ZAP-70, Zeta-chain-associated protein kinase 70 ; PKC- $\theta$, protein kinase C- $\theta$; PLC $\gamma 1$, phospholipase C gamma 1; JNK, c-Jun N-terminal kinase; RAS, retrovirus-associated DNA sequences; MEK, extracellular signal-regulated kinase kinase; ERK, extracellular signal-regulated kinase; PI3K, phosphatidylinositol 3-kinase; mTOR, mammalian target of rapamycin; PTEN, phosphatase and tensin homolog; CK2, casein kinase 2; SKP2, S-phase kinase-associated protein 2; Bcl-xL, B-cell lymphoma-extra large; Bim, Bcl-2 interacting mediator of cell death

proliferation by restricting the cells from entering into cellular division cycle, which related to an impaired production of autocrine growth factor IL-2 [77]. CD28 signal is involved in the modulation, as the induction of IL-2 upon CD28 engagement has been well documented. Another study pointed out that IL-2, IL-7 and IL-15 can overcome PD-1-mediated inhibition of $\mathrm{T}$ cell proliferative responses through transcriptional regulation of transcription 5 (STAT5) [72]. PD-1 blocks cell cycle progression through the G1 phase by inhibiting S-phase kinase-associated protein 2 (SKP2) and Smad3 activation, which is mediated by PI3K-AKT, RAS and MEK-ERK pathways, and leading to the downregulation of glycolytic enzyme activity and reduction of T cell expansion [71]. Decreased expression of PD-1 on peripheral blood T cells can enhance T cell proliferation, produce proinflammatory cytokines (IFN- $\gamma$,
IL-2 and IL-12) and reduce anti-inflammatory cytokine secretion in human coronary artery disease [78].

Accumulating evidence suggests that PD-1/PD-L1 interactions play a role in the differentiation of activated $\mathrm{T}$ cells. PD-L1Ig treatment altered $\mathrm{T}$ cell differentiation by decreasing the percentages of Th1 and Th17 cells as well as increasing Th2 cells and Tregs in spleens of EAN rats [58]. Meanwhile, phosphorylated PI3K, AKT, and mTOR were suppressed, indicating a pivotal role of PI3K-AKT-mTOR axis in regulating $\mathrm{T}$ cell differentiation affected by PD-L1. Furthermore, the overexpression of PD-L1 induces Th1 cells converting into Tregs, shielding immune-deficient murine hosts from GvHD after transplantation [79]. This phenotype transformation of Th 1 cells is associated with SHP1/2 recruitment and STAT1 inactivation, dependent on the PD-1/ PD-L1 signaling [79].

Tregs are involved in peripheral tolerance modulation by inhibiting pathogenic effector T cell-mediated tissue damage [80]. Tregs are expressed the transcription factor forkhead box protein P3 (Foxp3), which divided into two subpopulations: naturally occurring (nTreg) and induced Treg (iTreg). PD-L1 is constitutively expressed by Tregs. Due to a key role of PD-1/PD-L1 and Tregs in the maintenance of peripheral tolerance, a large amount of studies have focused on the regulation of PD-1/PD-L1 on Treg differentiation and functions. When naïve $\mathrm{CD} 4^{+} \mathrm{T}$ cells were co-cultured with PD- $1^{-1-}$ APCs in the presence of anti-CD3 and transforming growth factor beta (TGF- $\beta$ ), decreased Foxp $3^{+}$Tregs were observed [81]. Besides, PD-L1Ig enhanced the maintainment of Foxp3 expression on iTregs and promoted suppressive efficiency of iTregs. In mechanistic experiments, the levels of AKT, mTOR and S6 ribosomal protein phosphorylation were significantly diminished when naïve $\mathrm{T}$ cells were cultured in the presence of PD-L1, since PD-L1 upregulated the expression of PTEN which antagonizes the PI3K-AKT pathway [81]. Another study reported the intrinsic function of PD-1 in maintaining Foxp3 stability by downregulating endo-lysosomal protease asparaginyl endopeptidase (AEP) in iTregs during experimental autoimmune colitis and GvHD [82]. Experimental autoimmune uveitis (EAU) is a mouse model of human autoimmune uveitis. Muhammad et al. recently demonstrated that a protective role of Treg in preventing the mice from EAU was PD-1-dependent [83]. Investigation of pregnancy in animal models also suggested an important role of PD-1/PD-L1 and Tregs interactions in fetomaternal tolerance. PD-L1 blockade led to decreased allogeneic fetal survival rates, associated with increased Th17 cells and a reduction of Tregs [84]. Importantly, mice with partial Foxp3 insufficiency developed early-onset lympho-proliferation and lethal autoimmune pancreatitis when PD-1 is deficient, which can be rescued by the transfer of PD-1-Foxp $3^{+}$Tregs [85]. Based on these studies, we conclude that PD-1/PD-L1 signaling preferentially pushes $\mathrm{T}$ 
cells toward an inhibitory Treg fate, while the regulation of PD-1/PD-L1 and Tregs is not completely overlapped regarding peripheral immune tolerance. PD-1-deficient Tregs were sufficient to rescue the autoimmune phenotype, indicating that PD-1 signaling reduces immunosuppressive function of Tregs [85]. Furthermore, PD-1 may also exert negative effects on Treg-mediated immunosuppression in tumor and chronic infection [86, 87]. Different immune status and local microenvironment may partially explain the discrepant findings regarding the effect of PD-1/PD-L1 on Treg functions.

In 1992, Honjo and colleagues identified the expression of PD-1 was strongly induced upon programmed cell death and thereby played a role in apoptosis [88]. They discovered that overexpression of PD-1 cDNA failed to induce apoptosis of $\mathrm{T}$ cells, suggesting that PD-1 may not trigger the apoptotic signaling directly [89]. Subsequent studies indicated that the engagement of PD-1/PD-L1 can indirectly hinder $\mathrm{T}$ cell survival by impacting the expression of apoptotic-related genes [10, 90]. During T cell activation, CD28 costimulation and TCR signaling retain T cell-survival by upregulating the expression of B-cell lymphoma-extra large (Bcl-xL), an anti-apoptotic gene. PD-1 ligation hampered $\mathrm{Bcl}-\mathrm{xL}$ expression via limiting the PI3K activation, causing impaired T cell survival [10]. Specifically, PD-1 impacts the survival of anti-viral $\mathrm{T}$ cells in chronic infection. The expression of PD- 1 on $\mathrm{CD} 8^{+} \mathrm{T}$ cells (also known as cytotoxic T lymphocytes, CTLs) augmented their sensitivity to both spontaneous and CD95/Fas-induced apoptosis [91]. Similarly, PD-L1 enhanced the death of effector CD8 ${ }^{+} \mathrm{T}$ cells through the upregulation of pro-apoptotic molecule Bcl-2 interacting mediator of cell death (Bim), promoting the depletion of memory $\mathrm{CD} 8^{+} \mathrm{T}$ cells accordingly [90]. However, Pulko et al. found that PD-L1 deficiency increased the apoptosis and the susceptibility of effector $\mathrm{CD} 8^{+} \mathrm{T}$ cells to Ca-dependent and Fas ligand-induced killing by other CTLs, and downregulated Bcl-xL expression [92]. With the contradictory results, more efforts are needed to gain a better understanding of this issue.

\section{B Lymphocytes}

Immunoglobulin $\mathrm{G}$ oligoclonal bands (OCBs) were evident in cerebrospinal fluid (CSF) of most patients with MS and anti-CD20 therapies are increasingly used as DMTs in MS. $\mathrm{B}$ cells are believed to display a pathogenic role in MS.

PD-1 is expressed on many subpopulations of B cells. Germinal center (GC) B cells and plasma cells express PD-L1 [93-95]. Similar to T cells, a negative effect of PD-1 signaling on B cell function is strongly suggested. PD1-knockout mice developed high levels of auto-antibodies [96]. PD-L1 ${ }^{-/-}$B cells stimulated a high proliferation of $\mathrm{CD}^{+}{ }^{+} \mathrm{T}$ cells in vitro [48]. With the expression of PD-L1, Tregs inhibited autoreactive B cells and induced peripheral
B cell tolerance directly through PD-1 in vivo [97]. Cellular mechanisms include recruiting SHP2 to its phosphotyrosine and dephosphorylating key signal transducers of BCR signaling [12]. Elevated expression of PD-L1 on regulatory B (Breg) cells suppressed follicular helper T (Tfh)-cell expansion and differentiation via alterations in downstream signaling pathways following PD-1 ligation [98]. The reduction of Tfh cells limited B-cell fate by limiting both memory B cell development and terminal differentiation to plasma cells, which dramatically inhibited antibody production and subsequent humoral responses. Consistent with this, blockade of PD-L1 can enhance humoral immunity by upregulating the generation of Tfh cells [99], and blockade of PD- 1 can enhance antigen-specific immunoglobulin production [100]. However, PD-1 has also been reported to be essential for GC responses, including GC B cell survival, the formation and affinity of long-live plasma cells, optimal GC localization and activity of Tfh cells [101, 102]. It is worth mentioning that the expression of PD-L1 is increased, while PD-1 expression is decreased in GC B cells and PD-1 is upregulated in Tfh cells $[95,101]$. One reasonable explanation is that GC B cells downregulate PD-1 to reduce the interactions between B cells and Tfh cells by PD-L1-PD-1 ligation. In addition, PD-1/PD-L1 interactions between Tfh cells and $B$ cells dampen TCR signaling and reduce the ligand sensitivity of Tfh cells, thereby enforcing a stringent selection threshold for competing B cells to promote affinity maturation [102] (Fig. 3).

\section{Natural Killer Cells}

NK cells act as sentinels for detecting aberrant cells. Unlike $\mathrm{T}$ and $\mathrm{B}$ cells, NK cells mediate immune defense without prior antigen sensitization. They discriminate target cells such as infected or malignant cells through a molecular detection system including a variety of cell surface activating and inhibitory receptors. When activated, NK cells target cell killing through release of perforin- and granzyme-containing cytotoxic granules, which is accompanied by secretion of proinflammatory and immunoregulatory cytokines [103]. NK cells are significant players in MS/EAE. NK cell depletion before immunization diminished the onset and severity of EAE, along with decreased lymphocytes and DCs infiltration into the CNS (104). However, two main subsets of human NK cells have different effects on MS. NK cell subsets are increased in the CSF of MS patients, and the regulatory/effector $\left(\mathrm{CD} 56^{\text {bright }} \mathrm{CD} 16^{-} / \mathrm{CD} 56^{\mathrm{dim}} \mathrm{CD} 16^{+}\right)$ NK ratio is also increased remarkably [105]. Many current DMTs can increase the CD56 ${ }^{\text {bright }}$ regulatory NK cell population in peripheral blood, which has the capability to suppress autologous $\mathrm{CD}^{+} \mathrm{T}$ cell proliferation through direct cytotoxicity $[106,107]$. PD- 1 is highly expressed on a small percentage of human peripheral blood NK cells in one 


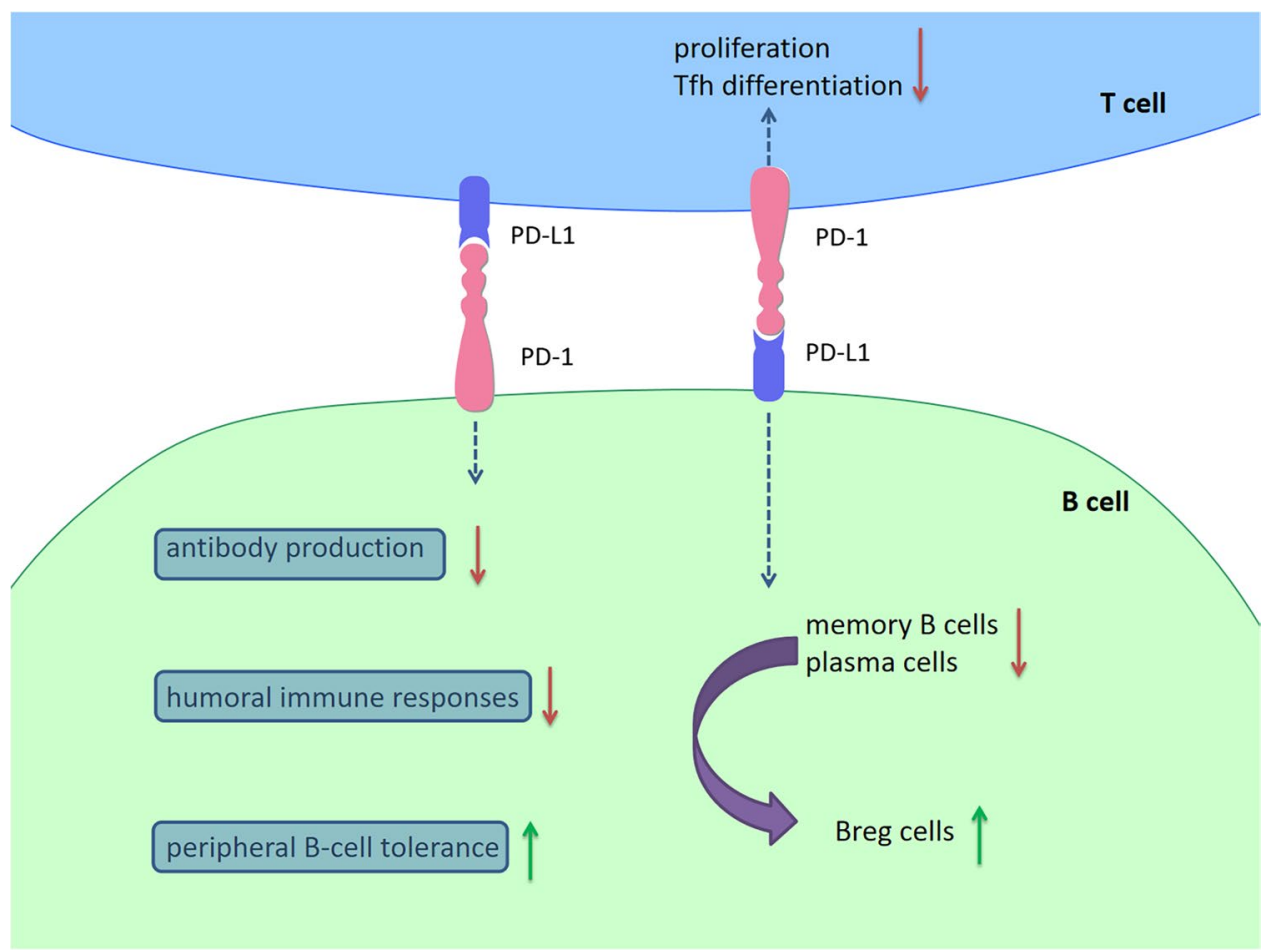

Fig. 3 PD-1/PD-L1 signaling in B cells. PD-1 is expressed on many subpopulations of B cells. GC B cells and plasma cells also express PD-L1. PD-L1 ${ }^{-1-} \mathrm{B}$ cells stimulated a high proliferation of $\mathrm{CD} 4^{+} \mathrm{T}$ cell in vitro. With the expression of PD-L1, Tregs inhibited autoreactive B cells and induced peripheral B cell tolerance directly through PD-1 in vivo. Elevated expression of PD-L1 on Breg cells suppressed the expansion and differentiation of Tfh cells via alterations in downstream signaling pathways following PD-1 ligation. The reduction of

quarter of healthy individuals, and a potential correlation is established between human cytomegalovirus (HCMV) seropositivity and the presence of PD- $1^{+} \mathrm{NK}$ cells. Latent chronic diseases such as viral infection may contribute to the induction and expression of PD-1 on NK cells (108). PD $-1^{+}$NK cells display a reduced proliferative capability in response to cytokines, low degranulation, impaired antitumor activity and increased apoptosis that can be partially restored by PD-1/PD-L1 blockade [108, 109]. Similar to T cells, PD-1 exerted its inhibitory effect on NK cells through interfering with AKT phosphorylation [109]. PD-L1 on NK cells can interact with PD-1 on DCs and inhibit the activation of DCs, exerting negative impacts on anti-tumor immunity [110]. During acute and chronic viral infection, liver-resident NK cells suppress the anti-viral responses of hepatic T cells via PD-1/PD-L1 interactions [111]. Besides, NK cells which highly expressed PD-L1 play an immunosuppressive role in autoimmunity. PD-L1 expression on NK cells was upregulated when stimulated by IL-18. Adoptive transfer of these cells into streptozotocin-treated mice led to a delayed diabetes development and partial disease prevention with the mechanism involving apoptosis induction of
Tfh cells limited B-cell fate by limiting both memory B cell development and terminal differentiation to plasma cells, which dramatically inhibited antibody production and subsequent humoral responses. Blockade of PD-L1 can enhance humoral immunity by upregulating the generation of Tfh cells, and blockade of PD-1 can enhance antigen-specific immunoglobulin production. Abbreviations: PD-1, programmed cell death 1; PD-L1, programmed cell death 1 ligand 1; GC, germinal center; Breg cells, regulatory B cells

activated antigen-specific $\mathrm{CD} 8^{+} \mathrm{T}$ cells [112]. However, a study of enteric microbial infection in mice suggested that increased PD-1 expression can boost the function of NK cells and promote protective immunity by increasing the expression and production of granzyme B and perforin of mucosal NK cells (113) (Fig. 4).

\section{Dendritic Cells}

DCs play both immunogenic and immunoregulatory roles in MS/EAE. Upon pathological stimulation, mature DCs activate naïve $T$ cells in the periphery and promote them to differentiate into effector cells, resulting in the release of proinflammatory cytokines. Activated T cells can be re-activated upon encounter with CNS-resident DCs which present myelin-derived epitopes [111]. Tolerogenic DCs are a steady state of immature, maturation-resistant DCs that express low levels of co-stimulatory molecules (CD80, CD86, and CD40), high levels of co-inhibitory molecules (PD-L1 and CD95L) and have an ability to induce Tregs instead of Th1/Th17 responses [112]. Tolerogenic DCs induce stable antigen-specific immunological 


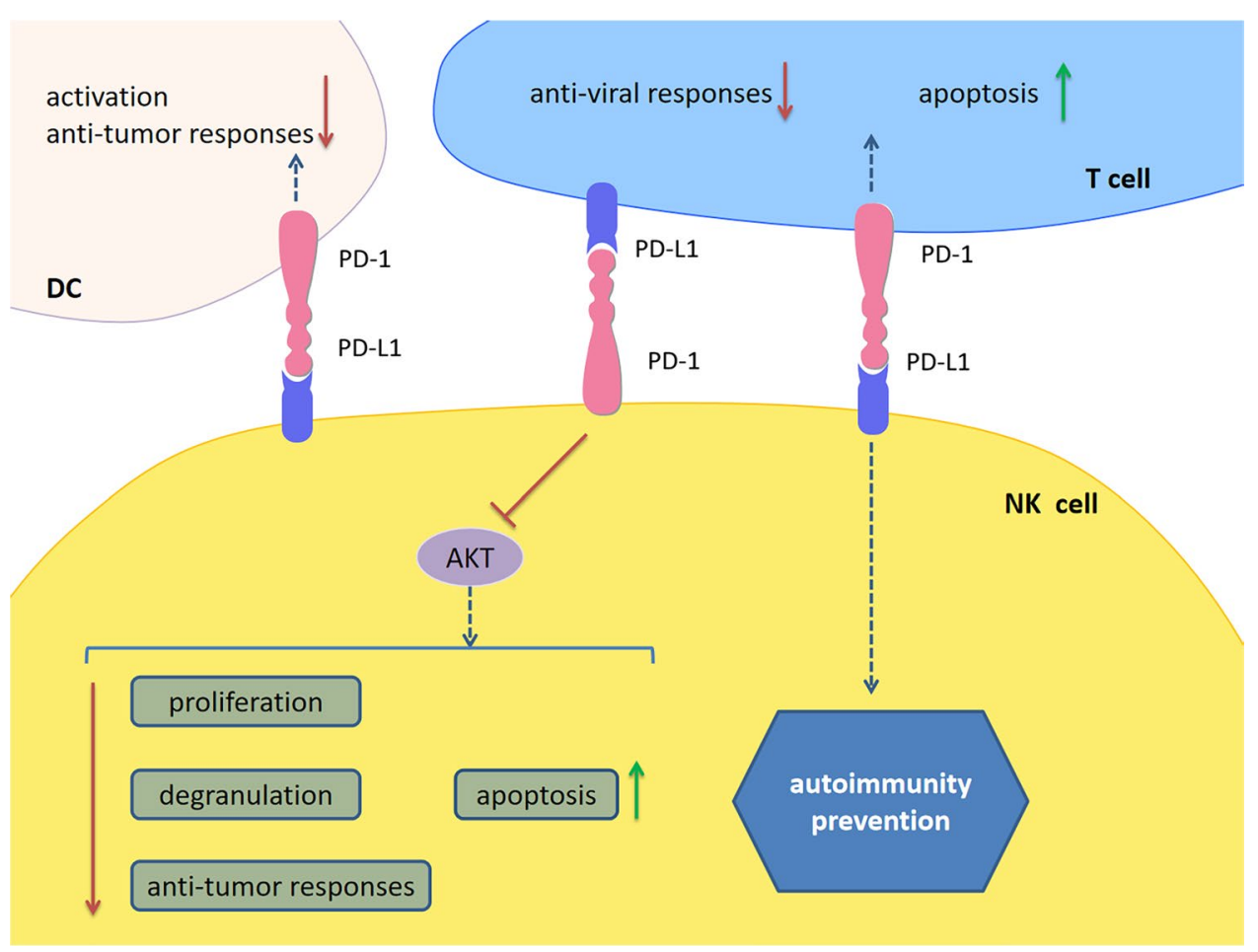

Fig. 4 PD-1/PD-L1 signaling in NK cells. PD- $1^{+}$NK cells display a reduced proliferative capability in response to cytokines, low degranulation, impaired anti-tumor activity and increased apoptosis that can be partially restored by PD-1/PD-L1 blockade. PD-1 exerts its inhibitory effects on NK cells through interfering with AKT phosphorylation. PD-L1 on NK cells can interact with PD-1 on DCs and then inhibit DCs activation, exerting negative impacts on anti-tumor

hyporesponsiveness in myelin-reactive $\mathrm{T}$ cells from RRMS patients [114]. Administration of tolerogenic DCs decreased the incidence and severity of EAE through the induction of Tregs, the reduction of Th1 and Th17 cells, and the production of IL-10 $(115,116)$.

Overexpressed PD-L1 in DCs may impair $\mathrm{CD}^{+}{ }^{+} \mathrm{T}$ cell-activation and IL-2 production in vitro [117]. Also, tolerogenic DCs enhance the expression of PD- 1 in T cells both in vivo and in vitro $[118,119]$. Interestingly, soluble PD-1 can induce a tolerogenic DC phenotype via reversing signaling by PD-L1 into DCs [117]. Due to the powerful role in immune tolerance induction, tolerogenic DCs that highly express PD-L1 have been considered a therapeutic target for GvHD and autoimmune diseases [118, 120]. Besides, PD-1 expression on DCs can negatively modulate DC functions and impede immune responses by interfering the production of DC-derived IL-12 and tumor necrosis factor alpha (TNF- $\alpha)$ [121]. It is inferred that PD-L1-expressing cells may have the potential to suppress $\mathrm{T}$ cell responses by directly engaging PD-1 on DCs and inhibiting the function of DCs. DC-DC interplay through PD-L1/ PD-1 may also play a role in immune modulation (Fig. 5). immunity. During acute and chronic viral infection, liver-resident NK cells suppress the anti-viral responses of hepatic $\mathrm{T}$ cells via PD-1/ PD-L1 interactions. Besides, NK cells which highly expressed PD-L1 play an immunosuppressive role in autoimmunity. Abbreviations: PD-1, programmed cell death 1; PD-L1, programmed cell death 1 ligand 1; NK cells: natural killer cells; DCs, dendritic cells

\section{Macrophages/Microglia}

Microglia are tissue macrophages in the CNS, playing a critical role for neural development, synaptic pruning and CNS homeostasis [122]. In MS/EAE, microglia are viewed as a "double edged sword." On one hand, activated microglia/ macrophages aggravate neuroinflammation through antigen presentation and proinflammatory cytokine secretion [123]. Microglia/macrophages can directly damage neurons by releasing inflammatory factors (reactive oxygen and nitrogen species) to trigger mitochondrial injury and axonal damage [124]. On the other hand, microglia/macrophages drive oligodendrocyte differentiation and initiate remyelination. Microglia can also clear myelin debris and apoptotic cells as well as promote neurogenesis by producing neurotrophic factors such as brain-derived neurotrophic factor (BDNF) and insulin-like growth factor 1 (IGF-1) [125].

PD-1-expressing macrophages exhibited an anti-inflammatory-like surface profile in both mice and human tumor settings [126]. PD-1 expression is negatively correlated to phagocytic ability of macrophages and blockade of PD-1/ PD-L1 enhanced anti-tumor responses, prolonged survival 


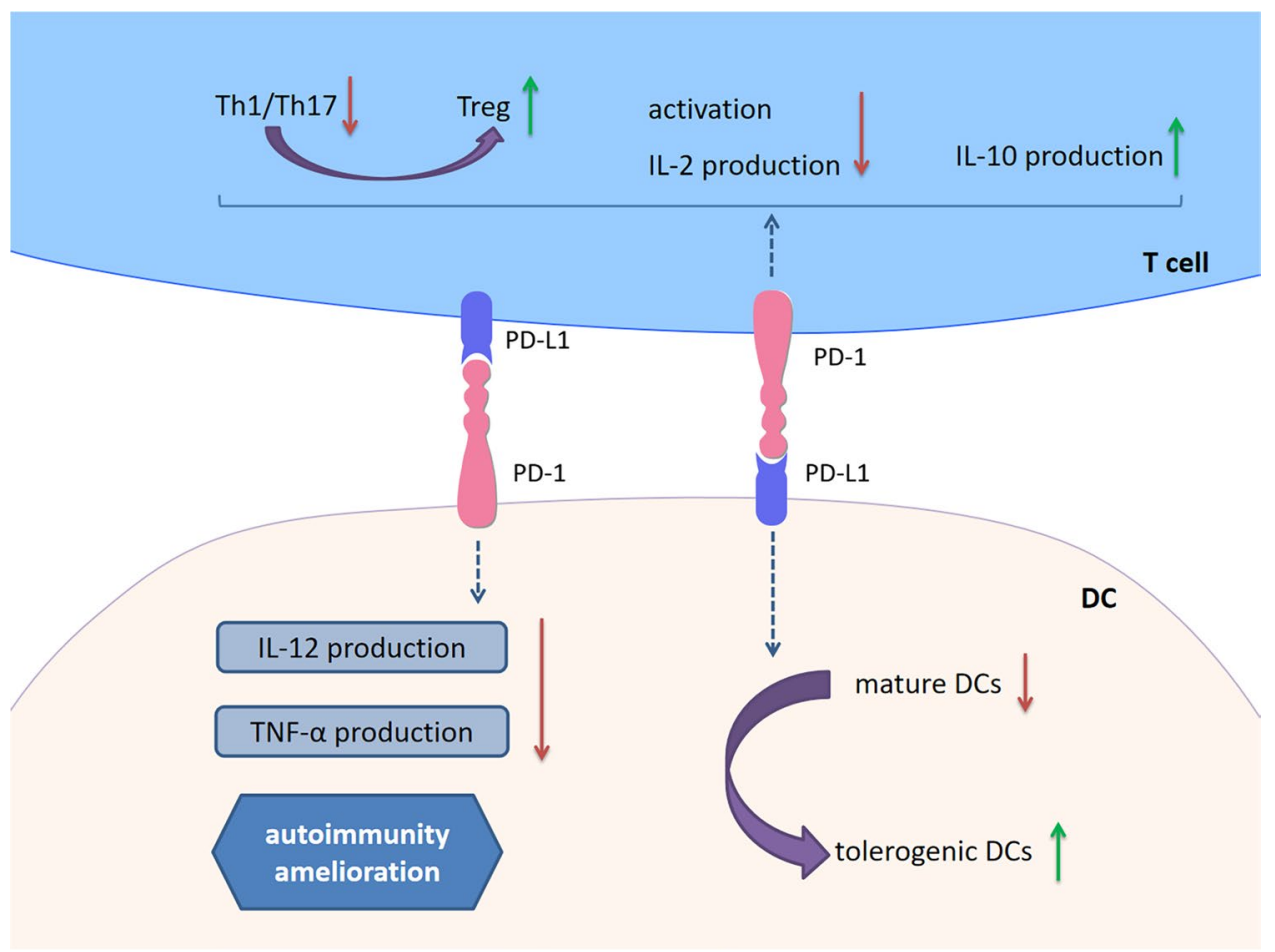

Fig. 5 PD-1/PD-L1 signaling in DCs. Overexpressed PD-L1 in DCs may impair $\mathrm{CD}^{+} \mathrm{T}$ cell activation and $\mathrm{IL}-2$ production in vitro. Tolerogenic DCs that highly express PD-L1 enhance the expression of PD-1 in T cells both in vivo and in vitro. Soluble PD-1 can induce a tolerogenic DC phenotype via reversing signaling by PD-L1 into DCs. Due to the powerful role in immune tolerance induction, tolerogenic DC has been considered a therapeutic target for autoimmune

through inhibiting proinflammatory to anti-inflammatory macrophages polarization [126, 127]. PD-L1 antibody treatment promoted cell proliferation of cultured bone marrowderived macrophages, which is related to the activation of the AKT-mTOR pathway. Transcriptomic profiles of macrophages have been switched into inflammatory phenotypes following PD-L1 antibody treatment [128] (Fig. 6).

During neuroinflammation, microglia upregulate the expression of both PD-1 and PD-L1, serving as a critical immune cell type that attenuates inflammatory responses and promotes neuronal repair. Upregulated expression of PD-1 in activated microglia can reduce proinflammatory cytokine production, inducing microglial polarization toward into the immunoregulatory type [129]. In mice model of spinal cord injury, PD-1 deficiency induced microglial polarization toward into the proinflammatory phenotype via STAT1 and nuclear factor kappa beta (NF- $\mathrm{kB})$ signaling [130]. It was recently discovered that the elevated expression of PD-L1 promoted anti-inflammatory microglial polarization after spinal cord injury, then improving motor function recovery and alleviating neuropathic pain via inhibiting the phosphorylation of p38 and ERK1/2 [131]. With the upregulation of PD-1 on infiltrating effector T cells in the diseases. Besides, PD-1 expression on DCs can negatively modulate DC functions and impede immune responses by interfering the production of DC-derived IL-12 and TNF- $\alpha$. Abbreviations: PD-1, programmed cell death 1; PD-L1, programmed cell death 1 ligand 1; DCs, dendritic cells; IL, interleukin; TNF- $\alpha$, tumor necrosis factor alpha

CNS, microglia are highly expressed PD-L1 and suppress T-cell responses via the PD-1/PD-L1 interactions, limiting detrimental immune-mediated damage [132]. Since the expression of PD-1 and PD-L1 can be upregulated on microglia simultaneously, the possibility of microglia interacting with themselves through the PD-1/PD-L1 pathway is worth exploring in the future (Fig. 7).

Taken together, the expression of PD-1 and PD-L1 on microglia/macrophages occurs as a response in the presence of different inflammatory milieu, altering cellular phenotypes through downstream signal transduction, then modulating innate and adaptive immune responses.

\section{Current Understanding of PD-1/PD-L1 in MS/ EAE}

Given that PD-1/PD-L1 emerges as a significant player in immune tolerance, the role of PD-1/PD-L1 signaling in MS/ EAE has received increasing attention. This section summarizes the role of PD-1/PD-L1 in the conditions of MS/ EAE (Fig. 8). 
Fig. 6 PD-1/PD-L1 signaling in macrophages. PD-1-expressing macrophages exhibit an antiinflammatory-like surface profile in tumor settings. PD-1 expression is negatively correlated to phagocytic ability of macrophages and blockade of PD-1/PD-L1 enhanced antitumor responses, prolonged survival through inhibiting proinflammatory to anti-inflammatory macrophages polarization. PD-L1 antibody treatment promotes cell proliferation of cultured bone marrow-derived macrophages, which is related to the activation of the AKTmTOR pathway. Transcriptomic profiles of macrophages have been switched into inflammatory phenotypes following PD-L1 antibody treatment. Abbreviations: PD-1, programmed cell death 1; PD-L1, programmed cell death 1 ligand 1

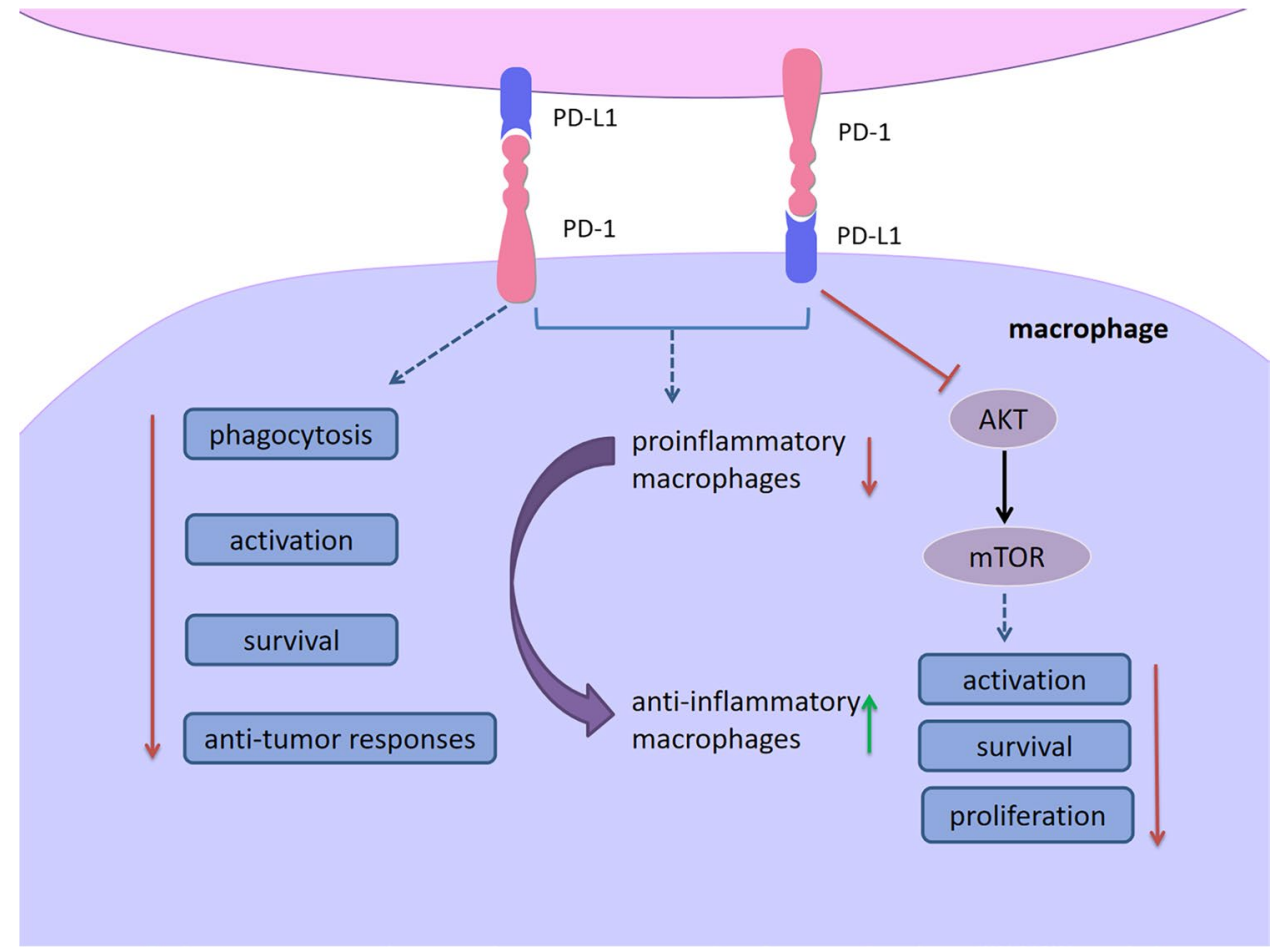

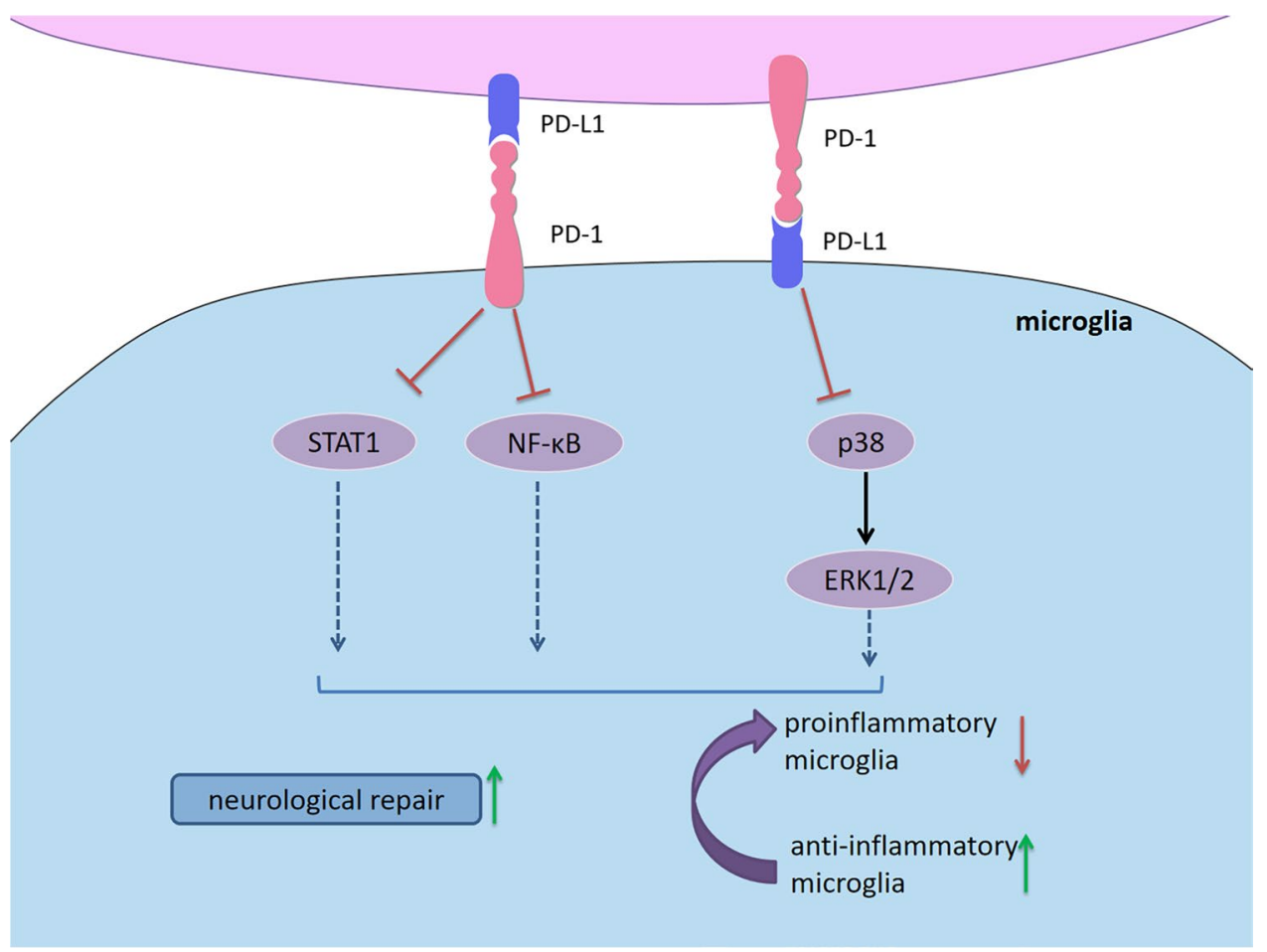

Fig. 7 PD-1/PD-L1 signaling in microglia. During neuroinflammation, microglia upregulate the expression of both PD-1 and PD-L1. Upregulated expression of PD-1 in activated microglia can reduce proinflammatory cytokine production, inducing microglial polarization toward into the immunoregulatory type. In mice model of spinal cord injury, PD-1 deficiency induces microglial polarization toward into the proinflammatory phenotype via STAT1 and NF- $\mathrm{KB}$ signaling. The elevated expression of PD-L1 promotes anti-inflammatory microglial polarization via inhibiting the phosphorylation of $\mathrm{p} 38$ and ERK1/2. With the upregulation of PD-1 on infiltrating effector T cells in the CNS, microglia are highly expressed PD-L1 and suppress T-cell responses via the PD-1/PD-L1 interactions, limiting detrimental immune-mediated damage. Abbreviations: PD-1, programmed cell death 1; PD-L1, programmed cell death 1 ligand 1; NF- $\mathrm{BB}$, nuclear factor kappa beta; ERK, extracellular signal-regulated kinase 


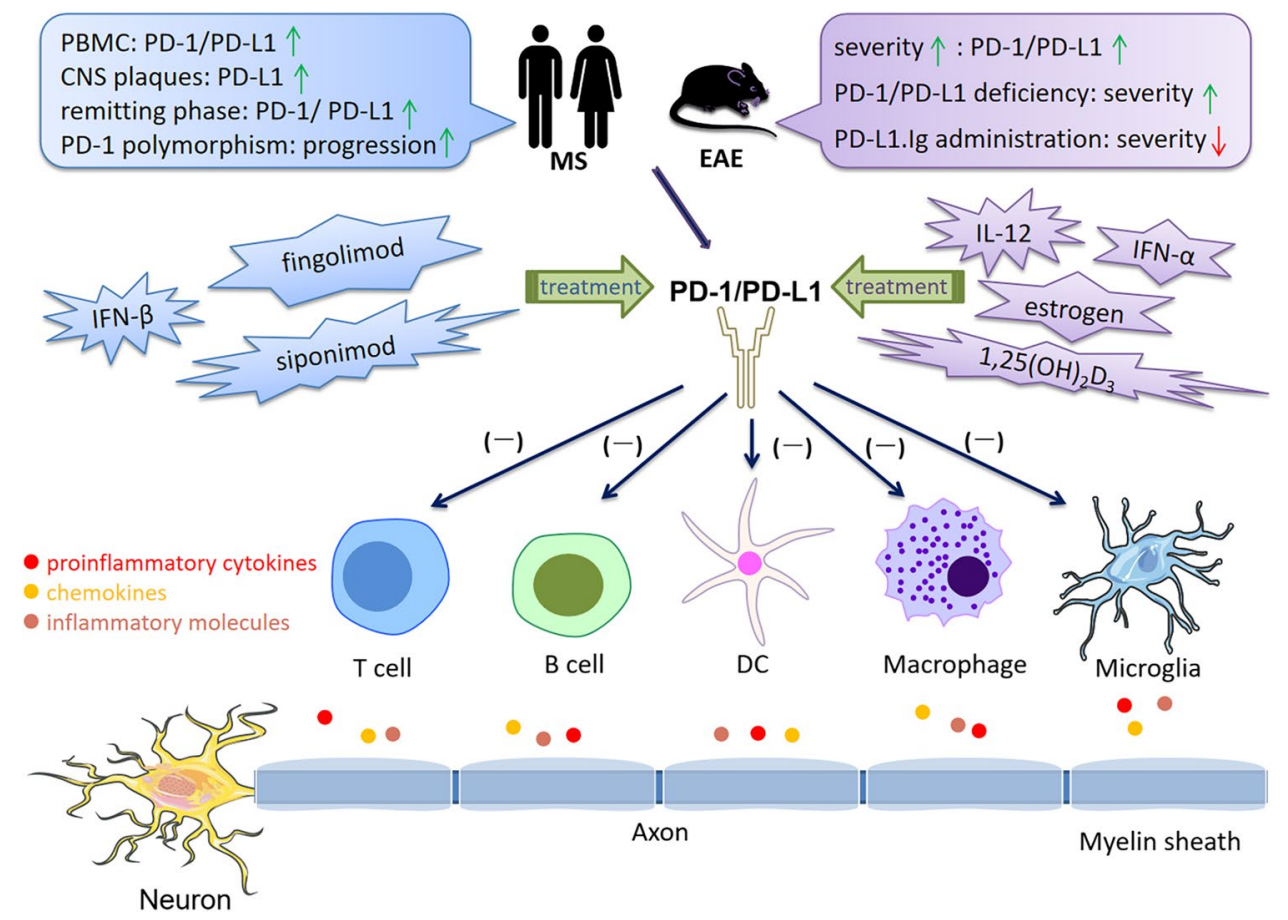

Fig. 8 Cell-based PD-1/PD-L1 immunoregulation in MS/EAE. There is a correlation between PD-1/PD-L1 expression and initiation along with disease progression. Compared to healthy individuals, the expression of PD-1/PD-L1 on PBMCs was significant reduced in RRMS patients. While PD-L1 expression on MS plaques was increased, PD-1-expressing T cells and PD-L1-expressing APCs in peripheral blood of remitting MS patients were significantly increased compared with acute MS patients. Importantly, an intronic $7146 \mathrm{G} / \mathrm{A}$ polymorphism within the $P d c d l$ gene is associated with a progressive disease course in MS. In EAE, the expression of PD-1/ PD-L1 was increased with worsening symptoms. Blockade or deficiency of PD-1/PD-L1 resulted in EAE exacerbation. Early treatment with PD-L1Ig fusion protein resulted in a long-lasting disease amelioration. Furthermore, upregulation of PD-1/PD-L1 is involved in the immunoregulation of many treatments for MS/EAE, including IFN- $\beta$, siponimod, fingolimod, IFN- $\alpha$, IL-12, estrogen and $1,25(\mathrm{OH})_{2} \mathrm{D}_{3}$. T

Compared to healthy individuals, the expression of $p d-1$ and $p d-l l$ in peripheral blood mononuclear cells (PBMCs) was significantly reduced in RRMS patients, suggesting the breakdown of immunological tolerance in MS [133, 134]. However, PD-L1 expression in MS plaques has been shown to be increased when compared to non-pathological human CNS tissues [135]]. Upon myelin basic protein (MBP) stimulation, PD-1-expressing T cells and PD-L1-expressing APCs in peripheral blood of remitting MS patients were significantly increased compared with acute MS patients, indicating a positive correlation between PD-1/PD-L1 expression and MS remission [136]. A potential explanation for these paradoxical results may be the heterogeneity of patients' baseline characteristics and disease course in these studies. Importantly, PD-1 polymorphism is suggested to be a genetic modifier of MS progression [47]. An intronic cells (Th1, Th17, CTLs), B cells, DCs, and macrophages/microglia play pathogenic role in MS/EAE. They produce proinflammatory cytokines, chemokines and molecules in the CNS, causing myelin injury, axonal damage and neuron loss. Upregulation of PD-1/PD-L1 inhibits over-reactive immune responses through inducing immunoinhibitory or tolerogenic immune cells, restricting neuroinflammation in MS/EAE. Furthermore, PD-1 and PD-L1 have been identified to be involved in the therapeutic responses for MS/EAE. Abbreviations: PD-1, programmed cell death 1; PD-L1, programmed cell death 1 ligand 1; MS, multiple sclerosis; EAE, experimental autoimmune encephalomyelitis; PBMC, peripheral blood mononuclear cell; RRMS, relapsing-remitting multiple sclerosis; APC, antigen-presenting cell; IFN, interferon; IL, interleukin; $1,25(\mathrm{OH})_{2} \mathrm{D}_{3}, 1,25$-dihydroxyvitamin D3; CTL, cytotoxic T lymphocytes; DC, dendritic cell; CNS, central nervous system

7146G/A polymorphism of $P d c d l$ gene is associated with a progressive disease course in German MS patients by impairing PD-1-mediated suppression of IFN- $\gamma$ secretion [47]. A latest prospective, longitudinal study measured the serum PD-L1 during pregnancy and postpartum in MS and the results showed that there was a trend of increased PD-L1 during the first trimester of pregnancy in patients without disease relapse, but did not achieve statistical significance [137]. In EAE, PD-1/PD-L1 can be expressed on infiltrating mononuclear cells within the meninges and PD-L1 is expressed on the endothelium, astrocytes and microglia $[138,139]$. The expression of PD-1 and PD-L1 was significantly increased with disease progression [139]. Blockade of PD-1 using neutralizing mAb resulted in disease exacerbation, associated with increased myelin oligodendrocyte glycoprotein (MOG)-reactive T-cell responses, anti-MOG 
antibody production and CNS lymphocyte infiltration [139]. In keeping with this, EAE mice with the deficiency of PD-1 and PD-L1 developed severe disease [22]. In active MOGinduced EAE, early treatment with PD-L1Ig fusion protein resulted in a long-lasting disease amelioration [140]. Collectively, these discoveries highlight a protective role of PD-1/ PD-L1 in EAE.

The number of memory Tregs are reduced expressing significantly high level of PD-1 in peripheral blood of RRMS patients [141]. Liu and colleagues identified a novel Treg subpopulation $\left(\mathrm{CD} 4^{+} \mathrm{FoxA} 1^{+} \mathrm{CD} 47^{+} \mathrm{CD} 69^{+} \mathrm{PD}-\mathrm{L} 1{ }^{\mathrm{hi}}{ }^{\mathrm{FoxP}} 3^{-}\right)$ in EAE and adoptive transfer of these Tregs suppressed EAE depending on the PD-L1 expression [142]. Furthermore, PD-L1 deficiency enhanced Th1 and Th17 responses in $\mathrm{EAE}$, and the numbers of $\mathrm{CD} 4^{+}$and $\mathrm{CD} 8^{+} \mathrm{T}$ cells in the CNS were significantly elevated [135]. Proinflammatory microRNA (miR)-155 is critical for T cell effector functions with miR-155-deficient mice being highly resistant to EAE due to the Th1 and Th17 differentiation defect. A recent study found that PD-1 deletion promotes EAE in miR-155-knockout mice by increasing Th1 and Th17 cell infiltration [42]. Adoptive transfer of Bregs, which highly express PD-L1, can suppress the incidence and severity of MOG-induced EAE by decreasing IFN- $\gamma$ and IL-17 production [98]. Estrogen is believed to engage in immunomodulation and contributes to disease protection in MS/EAE. PD-L1 selectively expressed by B cells was proven to be indispensable for estrogen-induced protection against EAE [143]. Nonetheless, depletion of PD-L1 on B cells did not affect the onset and severity of EAE [144]. When EAE was induced in DC-depleted mice, a high degree of inflammation was observed, indicating the capacity of DCs for peripheral tolerance [119]. Mechanistic experiments indicated that the interactions between DCs and T cells by PD-L1/PD-1 ligation led to T cell hyporesponsiveness to EAE [119]. Consistently, conditional knockout of PD-L1 in DCs aggravated EAE [144]. The upregulation of PD-L1 in DCs via DNA hypomethylation resulted in delayed progression of $\mathrm{EAE}$ [145], and tolerogenic DCs expressed a high level of PD-L1 were effective for EAE [118, 146]. However, Zozulya et al. found that intracerebral injection of PD-L1 ${ }^{-1-}$ DCs recruited regulatory $\mathrm{CD}^{+} \mathrm{T}$ cells into the $\mathrm{CNS}$ and then ameliorated EAE [147]. It seems that PD-L1 on DCs is pivotal to maintain the susceptibility and reactivity of both pathogenic and protective T cells in EAE.

PD-L1 on microglia/macrophages plays a role in restricting neuroinflammation. Estrogen treatment enhanced PD-L1 expression on peripheral macrophages, which may contribute to its efficacy for EAE [148]. Previous studies revealed that PD-L1 on microglia can inhibit antigen-specific T cell activation, Th1 differentiation and cytokine production in vitro [132, 149]. PD-L1 expression on microglia/infiltrating macrophages has been shown to be increased in EAE.
The role of PD-1/PD-L1 on NK cells in MS/EAE remains unclear. It is well documented that PD-1/PD-L1 signaling regulates the functions of NK cells playing a crucial role on MS pathology. More efforts are needed to explore PD-1/ PD-L1 on NK cells as a potential target in the future.

PD-1 and PD-L1 have been identified to be involved in therapeutic mechanisms of MS/EAE. Both short- and longterm injection of IFN- $\beta$ upregulated the expression of PD-L1 in PBMCs of RRMS patients [150, 151]. A randomized controlled trial of siponimod (a selective sphingosine-1-phosphate receptor 1 and 5 modulator) indicated that treating SPMS with siponimod for 9-12 months increased circulating Tregs proliferation and upregulated PD-1 expression on $\mathrm{CD}^{+}{ }^{+} \mathrm{T}$ cells [152]. Similarly, PD- 1 expression on Tfh cells in the peripheral blood was increased following fingolimod treatment (12-month) in MS (153). Sustained lowdose IFN- $\alpha$ showed prophylactic and therapeutic efficacy in EAE by upregulating the mRNA expression of PD-1 on splenocytes (154). IL-12 administration can suppress EAE by increasing PD-L1 expression on CD11 ${ }^{+}$APCs via an IFN- $\gamma$-dependent manner [155]. Several studies have unraveled that mechanisms of estrogen to prevent EAE also include the upregulation of PD-1/PD-L1 [143, 146, 148, 156]. We have previously demonstrated that tolerogenic DCs induced by 1,25-dihydroxyvitamin $\mathrm{D} 3\left(1,25(\mathrm{OH})_{2} \mathrm{D}_{3}\right)$ are effective for EAE and potential therapeutic effects can be related to increased expression of PD-1 on T cells [118]. In summary, PD-1 and PD-L1 may serve as a promising target for MS/ EAE.

\section{Mechanisms of Regulating PD-1/PD-L1 Expression}

Since PD-1/PD-L1 ligation plays a role in maintaining immune homeostasis and tolerance, a better understanding of biological processes that regulate PD-1 and PD-L1 expression is helpful. The expression of PD-L1 and PD-1 can be tightly regulated via a complex manner, involving different signaling pathways, genomic and epigenetic parameters (summarized in Table 2).

\section{Regulation of PD-L1 Expression}

Expression of $p d-l l$ gene has been shown to be controlled by inflammatory milieu. Multiple proinflammatory cytokines are prominent soluble inducers for PD-L1, including TNF- $\alpha$, IL-17, IFN- $\alpha$, IFN- $\beta$, IFN- $\gamma$, IL-2, IL-7, IL-15, IL-21 and IL-27 [160-165]. IL-18 derived from cancer cells can promote PD-L1 expression and IL-10 production [166]. IL-6, IL-1 $\beta$, TNF- $\alpha$, IL-10, and IL-27 increase PD-L1 expression on DCs $[29,167,168]$. IFN- $\gamma$-mediated PD-L1 expression is mainly regulated by janus kinase 1 (JAK1)/JAK2-STAT1/ 


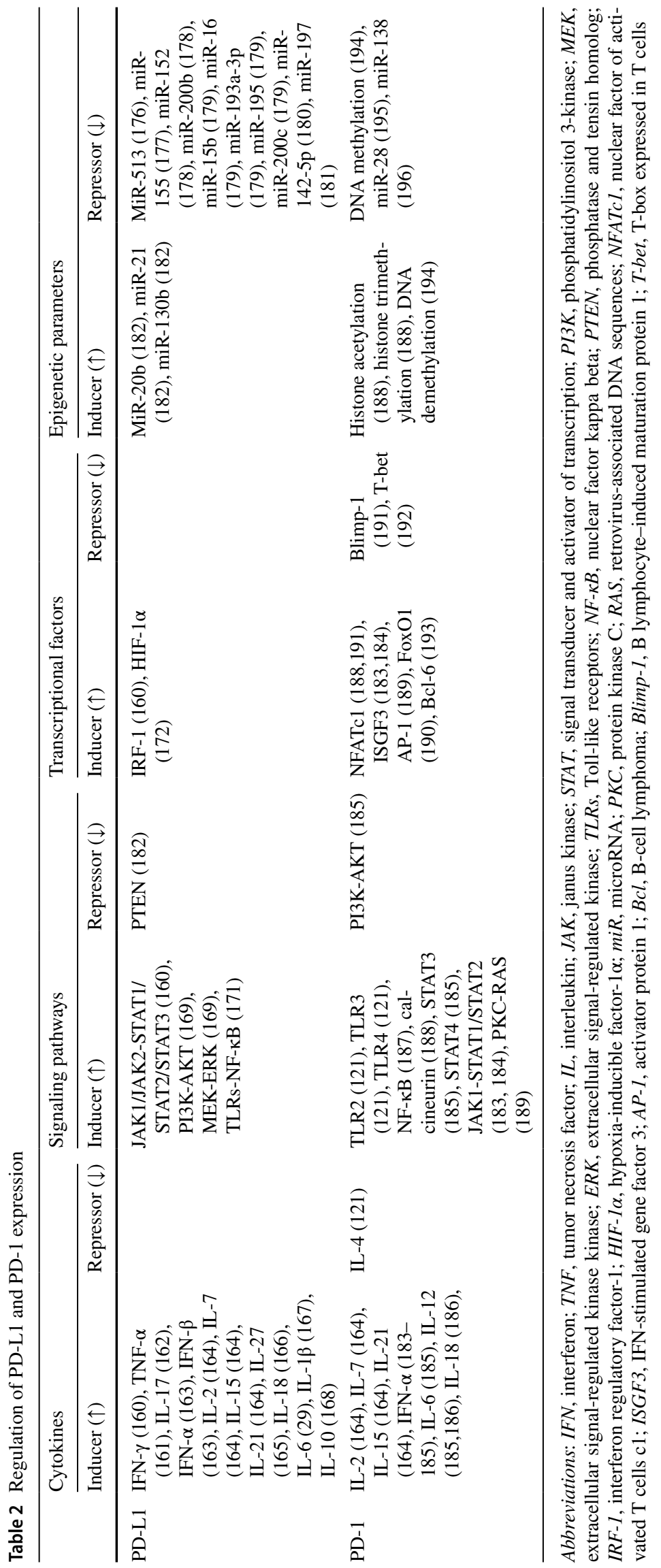


STAT2/STAT3, PI3K-AKT, MEK-ERK and NF-кB pathways and transcription factor interferon regulatory factor-1 (IRF-1) [160, 169, 170]. Notably, the activation of PI3KAKT and MEK-ERK can augment PD-L1 expression, while PD-1 signaling negatively regulates these two pathways decreasing PD-L1 expression and inhibiting T cell functions $[10,71,167]$. It is a negative feedback loop of immune cells to respond to microenvironment changes. Signal transduction via pathogen-associated molecular patterns (PAMPs) and Toll-like receptors (TLRs) results in nuclear translocation of NF- $\kappa B$, binding NF- $\kappa B$ to the PD-L1 promoter and inducing PD-L1 expression [171]. In the condition of hypoxia, hypoxia-inducible factor- $1 \alpha$ (HIF- $1 \alpha$ ) binds to the hypoxia-response element (HRE) in the PD-L1 proximal promoter and cooperates with the NF- $\kappa B$ pathway to promote PD-L1 transcription [172]. Besides, NF- $\mathrm{KB}$ also enhances PD-L1 protein stability [173]. There are paradoxical findings about the PD-L1 regulation by NF- $\mathrm{\kappa B}$. Inhibiting NF- $\kappa B$ pathway can induce tolerogenic DCs, which express higher level of PD-L1 than untreated-DCs [174, 175]. The diversity of PD-L1 regulation by NF- $\kappa B$ pathway in different immune cell types and the crosstalk among different signaling pathways may contribute to the discordance. MiRNAs function as post-transcriptional and translational regulators of PD-L1 expression [176-181]. Specifically, miR-20b, miR-21 and miR-130b can enhance PD-L1 expression by inhibiting the expression of PTEN, which is correlated with the activation of PI3K-AKT [182].

\section{Regulation of PD-1 Expression}

IL-2, IL-7, IL-15, IL-21, IFN- $\alpha$, IL-6, IL-12 and IL-18 were reported to promote the expression of PD-1 in different immune cells [164, 183]. IL-4 exerts negative effects on PD-1 expression in mice DCs, while IL-2, IL-6, IL-10, IFN- $\gamma$, IL-12, and TNF- $\alpha$ displayed no significant influences [121]. The upregulation of PD- 1 on B cells can be induced by TLR9 activation [95]. However, TLR9 significantly inhibits PD-1 expression on mice DCs, whereas TLR2, TLR3 and TLR4 induce PD-1 expression on DCs [121]. Following lipopolysaccharide (LPS) stimulation, PD-1 expression of macrophages can be induced by the activation of NF- $\mathrm{KB}$ [187]. Upon TCR stimulation of $\mathrm{CD} 8^{+} \mathrm{T}$ cells, calcineurin pathway is activated, resulting in translocation of nuclear factor of activated T cells $\mathrm{c} 1$ (NFATc1). NFATc1 binded to the conserved region-c (CR-C) enhances the promoter activity of PD-1 [188]. IL-6 and IL-12 can enhance PD-1 transcription on activated T cells by binding STAT3 and STAT4, respectively [185]. As for IFN- $\alpha$-induced PD-1 expression, the binding of IFN- $\alpha$ to its receptor leads to the activation of JAK1-STAT1/STAT2 pathway. STAT1, STAT2, and cytosolic IFN-responsive factor 9 (IRF9) proteins then form a transcription complex called IFN-stimulated gene factor 3
(ISGF3), which binds to the interferon-sensitive responsive element (ISRE) motif in the PD-1 promoter [183184]. Upon TCR stimulation, activator protein 1 (AP-1) is upregulated due to the PKC-RAS activation. AP-1 subunit c-Fos directly binds to the AP-1 site in the CR-B region of the $P d c d l$ locus and increase PD-1 expression [189]. As discussed before, PD-1 signaling dampens TCR-dependent activation of PI3K-AKT pathway. A previous study demonstrated that the inhibition of PI3K-AKT can enhance the nuclear accumulation of the transcription factor FoxO1, which reinforces PD-1 expression [190]. The results highlight a positive feedback pathway of PD-1 expression, promoting $\mathrm{T}$ cell exhaustion and immune homeostasis during chronic infection. The binding of B lymphocyte-induced maturation protein 1 (Blimp-1) in $P d c d l$ gene lucos leads to the eviction of NFATc1 from its site and the formation of a repressive chromatin structure, inhibiting the expression of PD-1 [191]. Additionally, Blimp-1 can curtail PD-1 expression indirectly by repressing the expression of NFATc1 [191]. During chronic infection the expression of T-box expressed in T cells (T-bet) can be downregulated in exhausted $\mathrm{CD} 8^{+}$ $T$ cells (highly express PD-1), while the over-expression of T-bet reduces the expression of PD-1 through binding to upstream regulatory elements of $P d c d l$ [192]. In accordance with this, transcription factor Bcl-6, acting as a PD-1 stimulator in Tfh cells, can inhibit the ability of T-bet to repress PD-1 transcription [193]. Epigenetic factors including histone modifications, DNA methylation and miRNAs can also affect the expression of PD-1 [188194]. However, DNA demethylation in CR-C and CR-B regions is not indispensable for PD-1 expression in immune cells, while may be important for durable PD-1 expression. It has been indicated that miR-28 and miR-138 can reduce the PD- 1 expression on T cells [195196], while the knowledge about regulating PD-1 expression by miRNAs remains insufficient. More research in this area is needed to fill the gaps.

\section{Concluding Remarks and Future Directions}

PD-1 and PD-L1 act as the brake of immune system, protecting self-tissue from autoimmunity. PD-1/PD-L1 strikes a balance between protective immunity and immunopathology by regulating the functions of immune cells. Exploring the precise effects and mechanisms of PD-1/PD-L1 on each cell type in certain immune microenvironments is of vital importance for clinical application of PD-1/PD-L1 targeting therapies. The functions of PD-1/PD-L1 are not completely overlapping $[128,140]$ and the underlying diversity needs to be further explored. Apart from its expression on immune cells, tissue expression of PD-1/PD-L1 also plays an immunoregulatory role $[138,197]$, which should be concerned in autoimmune diseases. The interactions between PD-1/ 
PD-L1 signaling and cellular metabolism have been indicated recently [198], providing a new promising research direction of PD-1/PD-L1.

A wave of studies regarding PD-1/PD-L1 in cancer and autoimmune diseases has provided valuable evidence for understanding the role of PD-1/PD-L1 in MS/EAE. Dynamic PD-1/PD-L1 expression during MS is inconclusive. To resolve the dispute, detailed baseline characteristics, clinical classifications and disease courses of MS should be taken into consideration. Most researches focused on the regulation of PD-1 on T cell activation in MS/EAE. Due to the involvement of B cells, NK cells, DCs, microglia/macrophages in MS pathology, the expression of PD-1/PD-L1 on these cells may also engage in MS development. Specifically, PD-1/PD-L1 not only limits autoimmunity in the CNS, but also exerts influences on acute and chronic pain, affective and cognitive behaviors $[199,200]$. Therefore, additional physiological functions of PD-1/PD-L1 in the CNS may provide new insights in MS pathogenesis. Based on current literature of PD-1/PD-L1 in MS/EAE, we conclude that PD-1/PD-L1 may be useful in indicating disease progression, monitoring therapeutic responses and predicting prognosis in MS, while the reliability as molecular biomarkers should be further validated.

Targeting PD-1/PD-L1 by direct administration of agonists or indirect upregulated expression may be potential specific treatments for MS, mirroring success of PD-1/ PD-L1 reinforcement in the treatment of autoimmunity. In order to design therapeutic strategies safely and effectively, a variety of open questions need to be addressed: [1] Which cell types should be targeted by PD-1/PD-L1 enhancement? Given that PD-1 and PD-L1 are both expressed on various immune cells, we cannot exclude the possibility of bidirectional interactions between PD-1 and PD-L1 on these cell types. Conditional knockout of PD-1/PD-L1 in certain immune cell types may be helpful. [2] What are the appropriate time, treatment regimens, and patients for PD-1/PD-L1 reinforcement? Due to the heterogeneity of disease course and therapeutic responses in different patients with MS, the best intervention timepoint, the feasible combination therapeutics regimens and selective patients who may benefit from PD-1/PDL1-based therapies should be confirmed to achieve an optimized therapeutic outcome. [3] PD-1/PD-L1 therapies used for alleviate neuroinflammation must have superior bioavailability across the BBB. The ideal carrier can overcome the obstacles and deliver PD-1/PD-L1-based drugs into the CNS. [4] Are there potentially adverse effects of PD-1/PD-L1 therapies? The overwhelming anti-tumor efficacy of PD-1/PD-L1 blockade is usually accompanied by immune-related adverse events [201]. PD-1/PD-L1 signaling plays a role in maintaining self-tolerance and preventing autoimmunity through general immune suppression, detrimental off-target effects may impair viral clearance, cause long-drawn-out opportunistic infections, and even increase the risk of cancer. Therefore, the negative impact of PD-1/PD-L1 reinforcement on the motility of immune surveillance and immune defense during long-term period should be thoroughly assessed. Identifying potential patients who will suffer from adverse effects following PD-1/PD-L1 administration may guide researchers to find a way to minimize these possible adverse events.

In conclusion, PD-1/PD-L1 plays an immunoregulatory role in a variety of immune cells including $\mathrm{T}$ cells, B cells, NK cells, DCs and macrophages/microglia in MS/EAE. PD-1/PD-L1 negatively regulates immune response. Furthermore, PD-1/PD-L1 is actively involved in therapeutic efficacy of current DMTs for MS. Updated knowledge of PD-1/PD-L1 provides theoretical foundation for manipulating PD-1/PD-L1 signaling pathway as a promising therapeutic target for MS in the future.

Author Contribution This manuscript was written by YM. JH, JZ, and TJ modified and edited the manuscript. All authors read and approved the final manuscript.

Funding This work was supported by grants from the General Program of the National Natural Science Foundation of China (No. 81671177), Natural Science Foundation of Jilin Province Science and Technology Development Plan Project (20190201043JC), Key Research and Development Project of Social Development Division of Jilin Science and Technology Department (20200403109SF), Special Project for Health Professionals of Jilin Provincial Finance Department (JLSWSRCZX2020-0056), as well as the grants from the Swedish Research Council (No. 2015-03005) and grants from the First hospital, Jilin University of China.

Data Availability Not applicable.

Code Availability Not applicable.

\section{Declarations}

Ethics Approval and Consent to Participate Not applicable.

Consent for Publication Not applicable.

Conflict of Interest The authors declare no competing interests.

Open Access This article is licensed under a Creative Commons Attribution 4.0 International License, which permits use, sharing, adaptation, distribution and reproduction in any medium or format, as long as you give appropriate credit to the original author(s) and the source, provide a link to the Creative Commons licence, and indicate if changes were made. The images or other third party material in this article are included in the article's Creative Commons licence, unless indicated otherwise in a credit line to the material. If material is not included in the article's Creative Commons licence and your intended use is not permitted by statutory regulation or exceeds the permitted use, you will need to obtain permission directly from the copyright holder. To view a copy of this licence, visit http://creativecommons.org/licenses/by/4.0/. 


\section{References}

1. Olsson T, Barcellos LF, Alfredsson L (2017) Interactions between genetic, lifestyle and environmental risk factors for multiple sclerosis. Nat Rev Neurol 13(1):25-36

2. Lagumersindez-Denis N, Wrzos C, Mack M, Winkler A, van der Meer F, Reinert MC et al (2017) Differential contribution of immune effector mechanisms to cortical demyelination in multiple sclerosis. Acta Neuropathol 134(1):15-34

3. Caravagna $C$ (2019) Intricate interplay between innate immune cells and TRMP2 in a mouse model of multiple sclerosis. J Neurosci 39(13):2366-2368

4. Henderson AP, Barnett MH, Parratt JD, Prineas JW (2009) Multiple sclerosis: distribution of inflammatory cells in newly forming lesions. Ann Neurol 66(6):739-753

5. Hemmer B, Kerschensteiner M, Korn T (2015) Role of the innate and adaptive immune responses in the course of multiple sclerosis. The Lancet Neurology 14(4):406-419

6. English C, Aloi JJ (2015) New FDA-approved disease-modifying therapies for multiple sclerosis. Clin Ther 37(4):691-715

7. Wingerchuk DM, Carter JL (2014) Multiple sclerosis: current and emerging disease-modifying therapies and treatment strategies. Mayo Clin Proc 89(2):225-240

8. Cree BAC, Mares J, Hartung H-P (2019) Current therapeutic landscape in multiple sclerosis: an evolving treatment paradigm. Curr Opin Neurol 32(3):365-377

9. Okazaki T, Chikuma S, Iwai Y, Fagarasan S, Honjo T (2013) A rheostat for immune responses: the unique properties of PD-1 and their advantages for clinical application. Nat Immunol 14(12):1212-1218

10. Parry RV, Chemnitz JM, Frauwirth KA, Lanfranco AR, Braunstein I, Kobayashi SV et al (2005) CTLA-4 and PD-1 receptors inhibit T-cell activation by distinct mechanisms. Mol Cell Biol 25(21):9543-9553

11. Sheppard KA, Fitz LJ, Lee JM, Benander C, George JA, Wooters $J$ et al (2004) PD-1 inhibits T-cell receptor induced phosphorylation of the ZAP70/CD3zeta signalosome and downstream signaling to PKCtheta. FEBS Lett 574(1-3):37-41

12. Okazaki T, Maeda A, Nishimura H, Kurosaki T, Honjo T (2001) PD-1 immunoreceptor inhibits B cell receptor-mediated signaling by recruiting src homology 2-domain-containing tyrosine phosphatase 2 to phosphotyrosine. Proc Natl Acad Sci USA 98(24):13866-13871

13. Keir ME, Butte MJ, Freeman GJ, Sharpe AH (2008) PD-1 and its ligands in tolerance and immunity. Annu Rev Immunol 26:677-704

14. Okazaki T, Honjo T (2007) PD-1 and PD-1 ligands: from discovery to clinical application. Int Immunol 19(7):813-824

15. Youngnak P, Kozono Y, Kozono H, Iwai H, Otsuki N, Jin H et al (2003) Differential binding properties of B7-H1 and B7-DC to programmed death-1. Biochem Biophys Res Commun 307(3):672-677

16. Keir ME, Liang SC, Guleria I, Latchman YE, Qipo A, Albacker LA et al (2006) Tissue expression of PD-L1 mediates peripheral T cell tolerance. J Exp Med 203(4):883-895

17. Collins M, Ling V, Carreno BM (2005) The B7 family of immune-regulatory ligands. Genome Biol 6(6):223

18. Latchman Y, Wood CR, Chernova T, Chaudhary D, Borde M, Chernova I et al (2001) PD-L2 is a second ligand for PD-1 and inhibits T cell activation. Nat Immunol 2(3):261-268

19. Tanegashima T, Togashi Y, Azuma K, Kawahara A, Ideguchi K, Sugiyama D et al (2019) Immune suppression by PD-L2 against spontaneous and treatment-related antitumor immunity. Clin Cancer Res 25(15):4808-4819
20. Akbari O, Stock P, Singh AK, Lombardi V, Lee WL, Freeman GJ et al (2010) PD-L1 and PD-L2 modulate airway inflammation and iNKT-cell-dependent airway hyperreactivity in opposing directions. Mucosal Immunol 3(1):81-91

21. Habicht A, Kewalaramani R, Vu MD, Demirci G, Blazar BR, Sayegh MH et al (2007) Striking dichotomy of PD-L1 and PD-L2 pathways in regulating alloreactive $\mathrm{CD} 4(+)$ and CD8(+) T cells in vivo. Am J Transplant 7(12):2683-2692

22. Carter LL, Leach MW, Azoitei ML, Cui J, Pelker JW, Jussif J et al (2007) PD-1/PD-L1, but not PD-1/PD-L2, interactions regulate the severity of experimental autoimmune encephalomyelitis. J Neuroimmunol 182(1-2):124-134

23. Ansari MJ, Salama AD, Chitnis T, Smith RN, Yagita H, Akiba H et al (2003) The programmed death-1 (PD-1) pathway regulates autoimmune diabetes in nonobese diabetic (NOD) mice. J Exp Med 198(1):63-69

24. Martin-Orozco N, Wang YH, Yagita H, Dong C (2006) Cutting edge: programmed death (PD) ligand-1/PD-1 interaction is required for CD8+ T cell tolerance to tissue antigens. J Immunol 177(12):8291-8295

25. Menke J, Lucas JA, Zeller GC, Keir ME, Huang XR, Tsuboi $\mathrm{N}$, et al. Programmed death 1 ligand (PD-L) 1 and PD-L2 limit autoimmune kidney disease: distinct roles. Journal of immunology (Baltimore, Md : 1950). 2007;179(11):7466-77.

26. Mataki N, Kikuchi K, Kawai T, Higashiyama M, Okada Y, Kurihara C et al (2007) Expression of PD-1, PD-L1, and PD-L2 in the liver in autoimmune liver diseases. Am J Gastroenterol 102(2):302-312

27. Pauken KE, Torchia JA, Chaudhri A, Sharpe AH, Freeman GJ. Emerging concepts in PD-1 checkpoint biology. Seminars in immunology. 2021:101480.

28. Dong H, Strome SE, Salomao DR, Tamura H, Hirano F, Flies DB et al (2002) Tumor-associated B7-H1 promotes T-cell apoptosis: a potential mechanism of immune evasion. Nat Med 8(8):793-800

29. Curiel TJ, Wei S, Dong H, Alvarez X, Cheng P, Mottram P et al (2003) Blockade of B7-H1 improves myeloid dendritic cellmediated antitumor immunity. Nat Med 9(5):562-567

30. Fritz JM, Lenardo MJ. Development of immune checkpoint therapy for cancer. J Exp Med. 2019.

31. Hirano F, Kaneko K, Tamura H, Dong H, Wang S, Ichikawa $\mathrm{M}$ et al (2005) Blockade of B7-H1 and PD-1 by monoclonal antibodies potentiates cancer therapeutic immunity. Cancer Res 65(3):1089-1096

32. Zhang L, Gajewski TF, Kline J (2009) PD-1/PD-L1 interactions inhibit antitumor immune responses in a murine acute myeloid leukemia model. Blood 114(8):1545-1552

33. Brahmer JR, Drake CG, Wollner I, Powderly JD, Picus J, Sharfman WH et al (2010) Phase I study of single-agent antiprogrammed death-1 (MDX-1106) in refractory solid tumors: safety, clinical activity, pharmacodynamics, and immunologic correlates. J Clin oncol 28(19):3167-3175

34. Ansell SM, Lesokhin AM, Borrello I, Halwani A, Scott EC, Gutierrez M et al (2015) PD-1 blockade with nivolumab in relapsed or refractory Hodgkin's lymphoma. N Engl J Med 372(4):311-319

35. Herbst RS, Soria JC, Kowanetz M, Fine GD, Hamid O, Gordon MS et al (2014) Predictive correlates of response to the anti-PD-L1 antibody MPDL3280A in cancer patients. Nature 515(7528):563-567

36. Hargadon KM, Johnson CE, Williams CJ (2018) Immune checkpoint blockade therapy for cancer: an overview of FDA-approved immune checkpoint inhibitors. Int Immunopharmacol 62:29-39 
37. Mahoney KM, Atkins MB (2014) Prognostic and predictive markers for the new immunotherapies. Oncology (Williston Park) 28(Suppl 3):39-48

38. Teng F, Meng X, Kong L, Yu J (2018) Progress and challenges of predictive biomarkers of anti PD-1/PD-L1 immunotherapy: a systematic review. Cancer Lett 414:166-173

39. Nishimura H, Nose M, Hiai H, Minato N, Honjo T (1999) Development of lupus-like autoimmune diseases by disruption of the PD-1 gene encoding an ITIM motif-carrying immunoreceptor. Immunity 11(2):141-151

40. Nishimura H, Okazaki T, Tanaka Y, Nakatani K, Hara M, Matsumori A et al (2001) Autoimmune dilated cardiomyopathy in PD-1 receptor-deficient mice. Science (New York, NY) 291(5502):319-322

41. Wang J, Yoshida T, Nakaki F, Hiai H, Okazaki T, Honjo T (2005) Establishment of NOD-Pdcd1-/- mice as an efficient animal model of type I diabetes. Proc Natl Acad Sci USA 102(33):11823-11828

42. Zhang J, Braun MY (2014) PD-1 deletion restores susceptibility to experimental autoimmune encephalomyelitis in miR155-deficient mice. Int Immunol 26(7):407-415

43. Tahoori MT, Pourfathollah AA, Akhlaghi M, Daneshmandi S, Nicknam MH, Soleimanifar N. Association of programmed cell death-1 (PDCD-1) gene polymorphisms with rheumatoid arthritis in Iranian patients. Clinical and experimental rheumatology.29(5):763-7.

44. Nielsen C, Hansen D, Husby S, Jacobsen BB, Lillevang ST (2003) Association of a putative regulatory polymorphism in the PD-1 gene with susceptibility to type 1 diabetes. Tissue Antigens 62(6):492-497

45. Prokunina L, Castillejo-López C, Oberg F, Gunnarsson I, Berg L, Magnusson V et al (2002) A regulatory polymorphism in PDCD1 is associated with susceptibility to systemic lupus erythematosus in humans. Nat Genet 32(4):666-669

46. Huang CH, Wong RH, Wei JC, Tsay MD, Chen WC, Chen HY et al (2011) Effects of genetic polymorphisms of programmed cell death 1 and its ligands on the development of ankylosing spondylitis. Rheumatol (Oxford) 50(10):1809-1813

47. Kroner A, Mehling M, Hemmer B, Rieckmann P, Toyka KV, Maurer M et al (2005) A PD-1 polymorphism is associated with disease progression in multiple sclerosis. Ann Neurol 58(1):50-57

48. Hamel KM, Cao Y, Wang Y, Rodeghero R, Kobezda T, Chen L et al (2010) B7-H1 expression on non-B and non-T cells promotes distinct effects on T- and B-cell responses in autoimmune arthritis. Eur J Immunol 40(11):3117-3127

49. Postow MA, Sidlow R, Hellmann MD (2018) Immune-related adverse events associated with immune checkpoint blockade. N Engl J Med 378(2):158-168

50. Stamatouli AM, Quandt Z, Perdigoto AL, Clark PL, Kluger H, Weiss SA et al (2018) Collateral damage: insulin-dependent diabetes induced with checkpoint inhibitors. Diabetes 67(8):1471-1480

51. Wang CJ, Chou FC, Chu CH, Wu JC, Lin SH, Chang DM et al (2008) Protective role of programmed death 1 ligand 1 (PD-L1)in nonobese diabetic mice: the paradox in transgenic models. Diabetes 57(7):1861-1869

52. Subudhi SK, Zhou P, Yerian LM, Chin RK, Lo JC, Anders $\mathrm{RA}$ et al (2004) Local expression of B7-H1 promotes organspecific autoimmunity and transplant rejection. J Clin Investig 113(5):694-700

53. Her M, Kim D, Oh M, Jeong H, Choi I (2009) Increased expression of soluble inducible costimulator ligand (ICOSL) in patients with systemic lupus erythematosus. Lupus 18(6):501-507
54. Raptopoulou AP, Bertsias G, Makrygiannakis D, Verginis P, Kritikos I, Tzardi M et al (2010) The programmed death 1/programmed death ligand 1 inhibitory pathway is up-regulated in rheumatoid synovium and regulates peripheral $\mathrm{T}$ cell responses in human and murine arthritis. Arthritis Rheum 62(7):1870-1880

55. Luo Q, Ye J, Zeng L, Luo Z, Deng Z, Li X et al (2018) Elevated expression of PD-1 on T cells correlates with disease activity in rheumatoid arthritis. Mol Med Rep 17(2):3297-3305

56. Reynolds J, Sando GS, Marsh OB, Salama AD, Evans DJ, Cook HT et al (2012) Stimulation of the PD-1/PDL-1 T-cell co-inhibitory pathway is effective in treatment of experimental autoimmune glomerulonephritis. Nephrol Dial Transplant 27(4):1343-1350

57. Zhou H, Xiong L, Wang Y, Ding L, Hu S, Zhao M et al (2016) Treatment of murine lupus with PD-LIg. Clin Immunol (Orlando, Fla) 162:1-8

58. Ding Y, Han R, Jiang W, Xiao J, Liu H, Chen X et al (2016) Programmed death ligand 1 plays a neuroprotective role in experimental autoimmune neuritis by controlling peripheral nervous system inflammation of rats. J Immunol 197(10):3831-3840

59. Thompson AJ, Banwell BL, Barkhof F, Carroll WM, Coetzee T, Comi G et al (2018) Diagnosis of multiple sclerosis: 2017 revisions of the McDonald criteria. The Lancet Neurol 17(2):162-173

60. Filippi M, Bar-Or A, Piehl F, Preziosa P, Solari A, Vukusic $\mathrm{S}$, et al. Multiple sclerosis. Nature reviews Disease primers. 2018;4(1):43

61. Dendrou CA, Fugger L, Friese MA (2015) Immunopathology of multiple sclerosis. Nat Rev Immunol 15(9):545-558

62. Nishimura H, Honjo T, Minato N (2000) Facilitation of beta selection and modification of positive selection in the thymus of PD-1-deficient mice. J Exp Med 191(5):891-898

63. Keir ME, Latchman YE, Freeman GJ, Sharpe AH (2005) Programmed death-1 (PD-1):PD-ligand 1 interactions inhibit TCR-mediated positive selection of thymocytes. J Immunol 175(11):7372-7379

64. Blank C, Brown I, Marks R, Nishimura H, Honjo T, Gajewski TF (2003) Absence of programmed death receptor 1 alters thymic development and enhances generation of CD4/CD8 double-negative TCR-transgenic T cells. J Immunol 171(9):4574-4581

65. Zucchelli S, Holler P, Yamagata T, Roy M, Benoist C, Mathis D (2005) Defective central tolerance induction in NOD mice: genomics and genetics. Immunity 22(3):385-396

66. Chen L, Flies DB (2013) Molecular mechanisms of T cell costimulation and co-inhibition. Nat Rev Immunol 13(4):227-242

67. Barber DL, Wherry EJ, Masopust D, Zhu B, Allison JP, Sharpe $\mathrm{AH}$ et al (2006) Restoring function in exhausted CD8 T cells during chronic viral infection. Nature 439(7077):682-687

68. Zinselmeyer BH, Heydari S, Sacristán C, Nayak D, Cammer M, Herz J et al (2013) PD-1 promotes immune exhaustion by inducing antiviral T cell motility paralysis. J Exp Med 210(4):757-774

69. Hatachi S, Iwai Y, Kawano S, Morinobu S, Kobayashi M, Koshiba M et al (2003) CD4+ PD-1+ T cells accumulate as unique anergic cells in rheumatoid arthritis synovial fluid. J Rheumatol 30(7):1410-1419

70. Yokosuka T, Takamatsu M, Kobayashi-Imanishi W, HashimotoTane A, Azuma M, Saito T (2012) Programmed cell death 1 forms negative costimulatory microclusters that directly inhibit T cell receptor signaling by recruiting phosphatase SHP2. J Exp Med 209(6):1201-1217

71. Patsoukis N, Brown J, Petkova V, Liu F, Li L, Boussiotis VA. Selective effects of PD-1 on Akt and Ras pathways regulate molecular components of the cell cycle and inhibit T cell proliferation. Science signaling. 2012;5(230):ra46.

72. Bennett F, Luxenberg D, Ling V, Wang IM, Marquette K, Lowe D et al (2003) Program death-1 engagement upon TCR activation 
has distinct effects on costimulation and cytokine-driven proliferation: attenuation of ICOS, IL-4, and IL-21, but not CD28, IL-7, and IL-15 responses. J Immunol 170(2):711-718

73. Patsoukis N, Li L, Sari D, Petkova V, Boussiotis VA (2013) PD-1 increases PTEN phosphatase activity while decreasing PTEN protein stability by inhibiting casein kinase 2. Mol Cell Biol 33(16):3091-3098

74. Hui E, Cheung J, Zhu J, Su X, Taylor MJ, Wallweber HA et al (2017) T cell costimulatory receptor CD28 is a primary target for PD-1-mediated inhibition. Science (New York, NY) 355(6332):1428-1433

75. Freeman GJ, Long AJ, Iwai Y, Bourque K, Chernova T, Nishimura $\mathrm{H}$ et al (2000) Engagement of the PD-1 immunoinhibitory receptor by a novel $\mathrm{B} 7$ family member leads to negative regulation of lymphocyte activation. J Exp Med 192(7):1027-1034

76. Rota G, Niogret C, Dang AT, Barros CR, Fonta NP, Alfei F et al (2018) Shp-2 is dispensable for establishing t cell exhaustion and for PD-1 signaling in vivo. Cell Rep 23(1):39-49

77. Carter L, Fouser LA, Jussif J, Fitz L, Deng B, Wood CR et al (2002) PD-1:PD-L inhibitory pathway affects both CD4(+) and CD8(+) T cells and is overcome by IL-2. Eur J Immunol 32(3):634-643

78. Lee J, Zhuang Y, Wei X, Shang F, Wang J, Zhang Y et al (2009) Contributions of PD-1/PD-L1 pathway to interactions of myeloid DCs with T cells in atherosclerosis. J Mol Cell Cardiol 46(2):169-176

79. Amarnath S, Mangus CW, Wang JCM, Wei F, He A, Kapoor $\mathrm{V}$, et al. The PDL1-PD1 axis converts human TH1 cells into regulatory $\mathrm{T}$ cells. Science translational medicine. 2011;3(111):111ra20.

80. Francisco LM, Sage PT, Sharpe AH (2010) The PD-1 pathway in tolerance and autoimmunity. Immunol Rev 236:219-242

81. Francisco LM, Salinas VH, Brown KE, Vanguri VK, Freeman GJ, Kuchroo VK et al (2009) PD-L1 regulates the development, maintenance, and function of induced regulatory T cells. J Exp Med 206(13):3015-3029

82. Stathopoulou C, Gangaplara A, Mallett G, Flomerfelt FA, Liniany LP, Knight D et al (2018) PD-1 inhibitory receptor downregulates asparaginyl endopeptidase and maintains Foxp3 transcription factor stability in induced regulatory $\mathrm{T}$ cells. Immunity 49(2):247-63.e7

83. Muhammad F, Wang D, Montieth A, Lee S, Preble J, Foster CS et al (2019) PD-1 melanocortin receptor dependent-Treg cells prevent autoimmune disease. Sci Rep 9(1):16941

84. D'Addio F, Riella LV, Mfarrej BG, Chabtini L, Adams LT, Yeung M et al (2011) The link between the PDL1 costimulatory pathway and Th17 in fetomaternal tolerance. J Immunol 187(9):4530-4541

85. Zhang B, Chikuma S, Hori S, Fagarasan S, Honjo T (2016) Nonoverlapping roles of PD-1 and FoxP3 in maintaining immune tolerance in a novel autoimmune pancreatitis mouse model. Proc Natl Acad Sci USA 113(30):8490-8495

86. Lowther DE, Goods BA, Lucca LE, Lerner BA, Raddassi K, van Dijk D, et al. PD-1 marks dysfunctional regulatory T cells in malignant gliomas. JCI insight. 2016;1(5).

87. Franceschini D, Paroli M, Francavilla V, Videtta M, Morrone S, Labbadia $\mathrm{G}$ et al (2009) PD-L1 negatively regulates CD4+CD25+Foxp3+ Tregs by limiting STAT-5 phosphorylation in patients chronically infected with $\mathrm{HCV}$. J Clin Investig 119(3):551-564

88. Ishida Y, Agata Y, Shibahara K, Honjo T (1992) Induced expression of PD-1, a novel member of the immunoglobulin gene superfamily, upon programmed cell death. EMBO J 11(11):3887-3895

89. Agata Y, Kawasaki A, Nishimura H, Ishida Y, Tsubata T, Yagita $\mathrm{H}$ et al (1996) Expression of the PD-1 antigen on the surface of stimulated mouse T and B lymphocytes. Int Immunol 8(5):765-772

90. Gibbons RM, Liu X, Pulko V, Harrington SM, Krco CJ, Kwon ED et al (2012) B7-H1 limits the entry of effector CD8(+) T cells to the memory pool by upregulating Bim. Oncoimmunol 1(7):1061-1073

91. Petrovas C, Casazza JP, Brenchley JM, Price DA, Gostick E, Adams WC et al (2006) PD-1 is a regulator of virusspecific CD8+ T cell survival in HIV infection. J Exp Med 203(10):2281-2292

92. Pulko V, Harris KJ, Liu X, Gibbons RM, Harrington SM, Krco $\mathrm{CJ}$ et al (2011) B7-h1 expressed by activated CD8 T cells is essential for their survival. J Immunol 187(11):5606-5614

93. Kamphorst AO, Ahmed R (2013) Manipulating the PD-1 pathway to improve immunity. Curr Opin Immunol 25(3):381-388

94. Doi T, Kanai T, Mikami Y, Sujino T, Jun L, Ono Y, et al. IgA plasma cells express the negative regulatory co-stimulatory molecule programmed cell death 1 ligand and have a potential tolerogenic role in the intestine. Biochem Biophys Res Commun. 2012;425(4):918-23.

95. Thibult M-L, Mamessier E, Gertner-Dardenne J, Pastor S, Just-Landi S, Xerri L et al (2013) PD-1 is a novel regulator of human B-cell activation. Int Immunol 25(2):129-137

96. Nishimura H, Minato N, Nakano T, Honjo T (1998) Immunological studies on PD-1 deficient mice: implication of PD-1 as a negative regulator for $\mathrm{B}$ cell responses. Int Immunol 10(10):1563-1572

97. Gotot J, Gottschalk C, Leopold S, Knolle PA, Yagita H, Kurts $\mathrm{C}$ et al (2012) Regulatory T cells use programmed death 1 ligands to directly suppress autoreactive B cells in vivo. Proc Natl Acad Sci USA 109(26):10468-10473

98. Khan AR, Hams E, Floudas A, Sparwasser T, Weaver CT, Fallon PG (2015) PD-L1hi B cells are critical regulators of humoral immunity. Nat Commun 6:5997

99. Hams E, McCarron MJ, Amu S, Yagita H, Azuma M, Chen L et al (2011) Blockade of B7-H1 (programmed death ligand 1) enhances humoral immunity by positively regulating the generation of $\mathrm{T}$ follicular helper cells. J Immunol 186(10):5648-5655

100. Cubas RA, Mudd JC, Savoye AL, Perreau M, van Grevenynghe $\mathrm{J}$, Metcalf T et al (2013) Inadequate T follicular cell help impairs B cell immunity during HIV infection. Nat Med 19(4):494-499

101. Good-Jacobson KL, Szumilas CG, Chen L, Sharpe AH, Tomayko MM, Shlomchik MJ (2010) PD-1 regulates germinal center B cell survival and the formation and affinity of long-lived plasma cells. Nat Immunol 11(6):535-542

102. Shi J, Hou S, Fang Q, Liu X, Liu X, Qi H (2018) PD-1 controls follicular $\mathrm{T}$ helper cell positioning and function. Immunity 49(2):264-74.e4

103. Fauriat C, Long EO, Ljunggren H-G, Bryceson YT (2010) Regulation of human NK-cell cytokine and chemokine production by target cell recognition. Blood 115(11):2167-2176

104. Winkler-Pickett R, Young HA, Cherry JM, Diehl J, Wine J, Back $T$ et al (2008) In vivo regulation of experimental autoimmune encephalomyelitis by NK cells: alteration of primary adaptive responses. J Immunol (Baltimore, Md : 1950) 180(7):4495-506

105. Rodríguez-Martín E, Picón C, Costa-Frossard L, Alenda R, Sainz de la Maza S, Roldán E et al (2015) Natural killer cell subsets in cerebrospinal fluid of patients with multiple sclerosis. Clin Exp Immunol 180(2):243-9

106. Martínez-Rodríguez JE, López-Botet M, Munteis E, Rio J, Roquer J, Montalban X et al (2011) Natural killer cell phenotype and clinical response to interferon-beta therapy in multiple sclerosis. Clin Immunol (Orlando, Fla) 141(3):348-356 
107. Skarica M, Eckstein C, Whartenby KA, Calabresi PA (2011) Novel mechanisms of immune modulation of natalizumab in multiple sclerosis patients. J Neuroimmunol 235(1-2):70-76

108. Pesce S, Greppi M, Tabellini G, Rampinelli F, Parolini S, Olive $\mathrm{D}$, et al. Identification of a subset of human natural killer cells expressing high levels of programmed death 1: a phenotypic and functional characterization. J Allergy Clin Immunol. 2017;139(1).

109. Liu Y, Cheng Y, Xu Y, Wang Z, Du X, Li C et al (2017) Increased expression of programmed cell death protein 1 on NK cells inhibits NK-cell-mediated anti-tumor function and indicates poor prognosis in digestive cancers. Oncogene 36(44):6143-6153

110. Iraolagoitia XLR, Spallanzani RG, Torres NI, Araya RE, Ziblat A, Domaica CI et al (2016) NK cells restrain spontaneous antitumor CD8+ $\mathrm{T}$ cell priming through PD-1/PD-L1 interactions with dendritic cells. J ilmmunol (Baltimore, Md : 1950) 197(3):953-61

111. Zhou J, Peng H, Li K, Qu K, Wang B, Wu Y, et al. Liver-resident NK cells control antiviral activity of hepatic T cells via the PD1-PD-L1 axis. Immunity. 2019;50(2).

112. Ehlers M, Papewalis C, Stenzel W, Jacobs B, Meyer KL, Deenen $R$ et al (2012) Immunoregulatory natural killer cells suppress autoimmunity by down-regulating antigen-specific CD8+ T cells in mice. Endocrinol 153(9):4367-4379

113. Solaymani-Mohammadi S, Lakhdari O, Minev I, Shenouda S, Frey BF, Billeskov R et al (2016) Lack of the programmed death-1 receptor renders host susceptible to enteric microbial infection through impairing the production of the mucosal natural killer cell effector molecules. J Leukoc Biol 99(3):475-482

114. Raïch-Regué D, Grau-López L, Naranjo-Gómez M, Ramo-Tello C, Pujol-Borrell R, Martínez-Cáceres E et al (2012) Stable antigen-specific T-cell hyporesponsiveness induced by tolerogenic dendritic cells from multiple sclerosis patients. Eur J Immunol 42(3):771-782

115. Mansilla MJ, Sellès-Moreno C, Fàbregas-Puig S, Amoedo J, Navarro-Barriuso J, Teniente-Serra A et al (2015) Beneficial effect of tolerogenic dendritic cells pulsed with MOG autoantigen in experimental autoimmune encephalomyelitis. CNS Neurosci Ther 21(3):222-230

116. Xie Z, Chen J, Zheng C, Wu J, Cheng Y, Zhu S et al (2017) 1,25-dihydroxyvitamin D-induced dendritic cells suppress experimental autoimmune encephalomyelitis by increasing proportions of the regulatory lymphocytes and reducing $\mathrm{T}$ helper type 1 and type 17 cells. Immunol 152(3):414-424

117. Kuipers H, Muskens F, Willart M, Hijdra D, van Assema FBJ, Coyle AJ et al (2006) Contribution of the PD-1 ligands/PD-1 signaling pathway to dendritic cell-mediated CD4+ T cell activation. Eur J Immunol 36(9):2472-2482

118. Cao Q, Zheng C, Xie Z, Liu L, Zhu J, Jin T. The change of PD1, PDL1 in experimental autoimmune encephalomyelitis treated by 1,25(OH)D. Journal of neuroimmunology. 2020;338:577079.

119. Yogev N, Frommer F, Lukas D, Kautz-Neu K, Karram K, Ielo D et al (2012) Dendritic cells ameliorate autoimmunity in the CNS by controlling the homeostasis of PD-1 receptor(+) regulatory $\mathrm{T}$ cells. Immunity 37(2):264-275

120. Vanherwegen A-S, Cook DP, Ferreira GB, Gysemans C, Mathieu C (2019) Vitamin D-modulated dendritic cells delay lethal graftversus-host disease through induction of regulatory $\mathrm{T}$ cells. $\mathrm{J}$ Steroid Biochem Mol Biol 188:103-110

121. Yao S, Wang S, Zhu Y, Luo L, Zhu G, Flies S et al (2009) PD-1 on dendritic cells impedes innate immunity against bacterial infection. Blood 113(23):5811-5818

122. Han J, Zhu K, Zhang X-M, Harris RA (2019) Enforced microglial depletion and repopulation as a promising strategy for the treatment of neurological disorders. Glia 67(2):217-231
123. Dong Y, Yong VW (2019) When encephalitogenic T cells collaborate with microglia in multiple sclerosis. Nat Rev Neurol 15(12):704-717

124. Nikić I, Merkler D, Sorbara C, Brinkoetter M, Kreutzfeldt M, Bareyre FM et al (2011) A reversible form of axon damage in experimental autoimmune encephalomyelitis and multiple sclerosis. Nat Med 17(4):495-499

125. Napoli I, Neumann H (2010) Protective effects of microglia in multiple sclerosis. Exp Neurol 225(1):24-28

126. Gordon SR, Maute RL, Dulken BW, Hutter G, George BM, McCracken MN et al (2017) PD-1 expression by tumour-associated macrophages inhibits phagocytosis and tumour immunity. Nature 545(7655):495-499

127. Dhupkar P, Gordon N, Stewart J, Kleinerman ES (2018) AntiPD-1 therapy redirects macrophages from an M2 to an M1 phenotype inducing regression of OS lung metastases. Cancer Med 7(6):2654-2664

128. Hartley GP, Chow L, Ammons DT, Wheat WH, Dow SW (2018) Programmed cell death ligand 1 (PD-L1) signaling regulates macrophage proliferation and activation. Cancer Immunol Res 6(10):1260-1273

129. He H, Zhou Y, Zhou Y, Zhuang J, He X, Wang S et al (2018) Dexmedetomidine mitigates microglia-mediated neuroinflammation through upregulation of programmed cell death protein 1 in a rat spinal cord injury model. J Neurotrauma 35(21):2591-2603

130. Yao A, Liu F, Chen K, Tang L, Liu L, Zhang K et al (2014) Programmed death 1 deficiency induces the polarization of macrophages/microglia to the M1 phenotype after spinal cord injury in mice. Neurotherapeutics 11(3):636-650

131. Kong F, Sun K, Zhu J, Li F, Lin F, Sun X, et al. PD-L1 improves motor function and alleviates neuropathic pain in male mice after spinal cord injury by inhibiting MAPK pathway. Frontiers in immunology. 2021;12:670646.

132. Hu J, He H, Yang Z, Zhu G, Kang L, Jing X et al (2016) Programmed death ligand-1 on microglia regulates Th1 differentiation via nitric oxide in experimental autoimmune encephalomyelitis. Neurosci Bull 32(1):70-82

133. Mohammadzadeh A, Rad IA, Ahmadi-Salmasi B (2018) CTLA4, PD-1 and TIM-3 expression predominantly downregulated in MS patients. J Neuroimmunol 323:105-108

134. Javan MR, Aslani S, Zamani MR, Rostamnejad J, Asadi M, Farhoodi M et al (2016) Downregulation of immunosuppressive molecules, PD-1 and PD-L1 but not PD-L2, in the patients with multiple sclerosis. Iran J Allergy Asthma Immunol 15(4):296-302

135. Ortler S, Leder C, Mittelbronn M, Zozulya AL, Knolle PA, Chen L et al (2008) B7-H1 restricts neuroantigen-specific T cell responses and confines inflammatory CNS damage: implications for the lesion pathogenesis of multiple sclerosis. Eur J Immunol 38(6):1734-1744

136. Trabattoni D, Saresella M, Pacei M, Marventano I, Mendozzi L, Rovaris M et al (2009) Costimulatory pathways in multiple sclerosis: distinctive expression of PD-1 and PD-L1 in patients with different patterns of disease. J Immunol (Baltimore, Md : 1950) 183(8):4984-93

137. Cuello JP, Martínez Ginés ML, Tejeda-Velarde A, Medina Heras S, García Domínguez JM, Fernández Velasco JI, et al. Cytokine profile during pregnancy predicts relapses during pregnancy and postpartum in multiple sclerosis. Journal of the neurological sciences. 2020;414:116811.

138. Liang SC, Latchman YE, Buhlmann JE, Tomczak MF, Horwitz BH, Freeman GJ et al (2003) Regulation of PD-1, PD-L1, and PD-L2 expression during normal and autoimmune responses. Eur J Immunol 33(10):2706-2716 
139. Salama AD, Chitnis T, Imitola J, Ansari MJI, Akiba H, Tushima F et al (2003) Critical role of the programmed death-1 (PD-1) pathway in regulation of experimental autoimmune encephalomyelitis. J Exp Med 198(1):71-78

140. Herold M, Posevitz V, Chudyka D, Hucke S, Groß C, Kurth F et al (2015) B7-H1 selectively controls TH17 differentiation and central nervous system autoimmunity via a novel nonPD-1-mediated pathway. J Immunol (Baltimore, Md : 1950) 195(8):3584-95

141. Sambucci M, Gargano F, De Rosa V, De Bardi M, Picozza M, Placido R et al (2018) FoxP3 isoforms and PD-1 expression by T regulatory cells in multiple sclerosis. Sci Rep 8(1):3674

142. Liu Y, Carlsson R, Comabella M, Wang J, Kosicki M, Carrion B et al (2014) FoxA1 directs the lineage and immunosuppressive properties of a novel regulatory $\mathrm{T}$ cell population in EAE and MS. Nat Med 20(3):272-282

143. Bodhankar S, Wang C, Vandenbark AA, Offner H (2011) Estrogen-induced protection against experimental autoimmune encephalomyelitis is abrogated in the absence of B cells. Eur J Immunol 41(4):1165-1175

144. Sage PT, Schildberg FA, Sobel RA, Kuchroo VK, Freeman GJ, Sharpe AH (2018) Dendritic cell PD-L1 limits autoimmunity and follicular $\mathrm{T}$ cell differentiation and function. J Immunol (Baltimore, Md : 1950) 200(8):2592-602

145. Chang C-B, Lee S-P, Chen W-M, Wang C-M, Song Y-C, Chan MWY, et al. Dendritic cell upregulation of programmed death ligand-1 via DNA demethylation inhibits experimental autoimmune encephalomyelitis. Journal of autoimmunity. 2020;107:102362.

146. Papenfuss TL, Powell ND, McClain MA, Bedarf A, Singh A, Gienapp IE et al (2011) Estriol generates tolerogenic dendritic cells in vivo that protect against autoimmunity. J Immunol (Baltimore, Md : 1950) 186(6):3346-55

147. Zozulya AL, Ortler S, Fabry Z, Sandor M, Wiendl H (2009) The level of B7 homologue 1 expression on brain DC is decisive for CD8 Treg cell recruitment into the CNS during EAE. Eur J Immunol 39(6):1536-1543

148. Seifert HA, Gerstner G, Kent G, Vandenbark AA, Offner H (2019) Estrogen-induced compensatory mechanisms protect IL-10-deficient mice from developing EAE. J Neuroinflammation 16(1):195

149. Magnus T, Schreiner B, Korn T, Jack C, Antel J, Ifergan I et al (2005) Microglial expression of the B7 family member B7 homolog 1 confers strong immune inhibition: Implications for immune responses and autoimmunity in the CNS. J Neurosci 25(10):2537-2546

150. Feng X, Bao R, Li L, Deisenhammer F, Arnason BGW, Reder AT (2019) Interferon- $\beta$ corrects massive gene dysregulation in multiple sclerosis: short-term and long-term effects on immune regulation and neuroprotection. EBioMedicine 49:269-283

151. Schreiner B, Mitsdoerffer M, Kieseier BC, Chen L, Hartung $\mathrm{HP}$, Weller $\mathrm{M}$ et al (2004) Interferon-beta enhances monocyte and dendritic cell expression of B7-H1 (PD-L1), a strong inhibitor of autologous T-cell activation: relevance for the immune modulatory effect in multiple sclerosis. J Neuroimmunol 155(1-2):172-182

152. Wu Q, Mills EA, Wang Q, Dowling CA, Fisher C, Kirch B, et al. Siponimod enriches regulatory $\mathrm{T}$ and $\mathrm{B}$ lymphocytes in secondary progressive multiple sclerosis. JCI insight. 2020;5(3).

153. Claes N, Dhaeze T, Fraussen J, Broux B, Van Wijmeersch B, Stinissen $P$ et al (2014) Compositional changes of B and T cell subtypes during fingolimod treatment in multiple sclerosis patients: a 12-month follow-up study. PloS one 9(10):e111115

154. Vasquez M, Consuegra-Fernández M, Aranda F, Jimenez A, Tenesaca S, Fernandez-Sendin M et al (2019) Treatment of experimental autoimmune encephalomyelitis by sustained delivery of low-dose IFN- $\alpha$. J Immunol (Baltimore, Md : 1950) 203(3):696-704

155. Cheng X, Zhao Z, Ventura E, Gran B, Shindler KS, Rostami A (2007) The PD-1/PD-L pathway is up-regulated during IL12-induced suppression of EAE mediated by IFN-gamma. J Neuroimmunol 185(1-2):75-86

156. Polanczyk MJ, Hopke C, Vandenbark AA, Offner H (2006) Estrogen-mediated immunomodulation involves reduced activation of effector T cells, potentiation of Treg cells, and enhanced expression of the PD-1 costimulatory pathway. J Neurosci Res 84(2):370-378

157. Bodhankar S, Galipeau D, Vandenbark AA, Offner H. PD-1 interaction with PD-L1 but not PD-L2 on B-cells mediates protective effects of estrogen against EAE. Journal of clinical \& cellular immunology. 2013;4(3):143-

158. Wang C, Dehghani B, Li Y, Kaler LJ, Proctor T, Vandenbark AA et al (2009) Membrane estrogen receptor regulates experimental autoimmune encephalomyelitis through up-regulation of programmed death 1. J Immunol 182(5):3294-3303

159. Wang C, Dehghani B, Li Y, Kaler LJ, Vandenbark AA, Offner H (2009) Oestrogen modulates experimental autoimmune encephalomyelitis and interleukin-17 production via programmed death 1. Immunol 126(3):329-335

160. Garcia-Diaz A, Shin DS, Moreno BH, Saco J, Escuin-Ordinas $\mathrm{H}$, Rodriguez GA et al (2017) Interferon receptor signaling pathways regulating PD-L1 and PD-L2 expression. Cell Rep 19(6):1189-1201

161. Li N, Wang J, Zhang N, Zhuang M, Zong Z, Zou J et al (2018) Cross-talk between TNF- $\alpha$ and IFN- $\gamma$ signaling in induction of B7-H1 expression in hepatocellular carcinoma cells. Cancer Immunol, immunother 67(2):271-283

162. Wang S, Wang G, Zhang L, Li F, Liu K, Wang Y et al (2020) Interleukin-17 promotes nitric oxide-dependent expression of PD-L1 in mesenchymal stem cells. Cell Biosci 10:73

163. Bazhin AV, von Ahn K, Fritz J, Werner J, Karakhanova S (2018) Interferon- $\alpha$ up-regulates the expression of PD-L1 molecules on immune cells through STAT3 and p38 signaling. Front Immunol 9:2129

164. Kinter AL, Godbout EJ, McNally JP, Sereti I, RobyO'Shea GAMA et al (2008) The common gamma-chain cytokines IL-2, IL-7, IL-15, and IL-21 induce the expression of programmed death-1 and its ligands. J Immunol (Baltimore, Md : 1950) 181(10):6738-46

165. Hirahara K, Ghoreschi K, Yang X-P, Takahashi H, Laurence $A$, Vahedi $G$ et al (2012) Interleukin-27 priming of $T$ cells controls IL-17 production in trans via induction of the ligand PD-L1. Immunity 36(6):1017-1030

166. Zhao Y, Shen M, Feng Y, He R, Xu X, Xie Y et al (2018) Regulatory B cells induced by pancreatic cancer cell-derived interleukin-18 promote immune tolerance via the PD-1/PD-L1 pathway. Oncotarget 9(19):14803-14814

167. Karakhanova S, Meisel S, Ring S, Mahnke K, Enk AH (2010) ERK/p38 MAP-kinases and PI3K are involved in the differential regulation of B7-H1 expression in DC subsets. Eur J Immunol 40(1):254-266

168. Karakhanova S, Bedke T, Enk AH, Mahnke K (2011) IL-27 renders DC immunosuppressive by induction of B7-H1. J Leukoc Biol 89(6):837-845

169. Gao Y, Yang J, Cai Y, Fu S, Zhang N, Fu X et al (2018) IFN$\gamma$-mediated inhibition of lung cancer correlates with PD-L1 expression and is regulated by PI3K-AKT signaling. Int J Cancer 143(4):931-943

170. Liu J, Hamrouni A, Wolowiec D, Coiteux V, Kuliczkowski $\mathrm{K}$, Hetuin D et al (2007) Plasma cells from multiple myeloma patients express B7-H1 (PD-L1) and increase expression 
after stimulation with IFN-\{gamma $\}$ and TLR ligands via a MyD88-, TRAF6-, and MEK-dependent pathway. Blood 110(1):296-304

171. Li H, Xia J-Q, Zhu F-S, Xi Z-H, Pan C-Y, Gu L-M, et al. LPS promotes the expression of PD-L1 in gastric cancer cells through NF- $\mathrm{\kappa B}$ activation. Journal of cellular biochemistry. 2018;119(12).

172. Guo R, Li Y, Wang Z, Bai H, Duan J, Wang S et al (2019) Hypoxia-inducible factor- $1 \alpha$ and nuclear factor- $\kappa B$ play important roles in regulating programmed cell death ligand 1 expression by epidermal growth factor receptor mutants in non-smallcell lung cancer cells. Cancer Sci 110(5):1665-1675

173. Lim S-O, Li C-W, Xia W, Cha J-H, Chan L-C, Wu Y et al (2016) Deubiquitination and stabilization of PD-L1 by CSN5. Cancer Cell 30(6):925-939

174. Morelli AE, Thomson AW (2007) Tolerogenic dendritic cells and the quest for transplant tolerance. Nat Rev Immunol 7(8):610-621

175. Yang M-G, Sun L, Han J, Zheng C, Liang H, Zhu J et al (2019) Biological characteristics of transcription factor RelB in different immune cell types: implications for the treatment of multiple sclerosis. Mol Brain 12(1):115

176. Gong AY, Zhou R, Hu G, Li X, Splinter PL, O'Hara SP et al (2009) MicroRNA-513 regulates B7-H1 translation and is involved in IFN-gamma-induced B7-H1 expression in cholangiocytes. J Immunol (Baltimore, Md : 1950) 182(3):1325-3

177. Yee D, Shah KM, Coles MC, Sharp TV, Lagos D (2017) MicroRNA-155 induction via TNF- $\alpha$ and IFN- $\gamma$ suppresses expression of programmed death ligand-1 (PD-L1) in human primary cells. J Biol Chem 292(50):20683-20693

178. Xie G, Li W, Li R, Wu K, Zhao E, Zhang Y, et al. Helicobacter pylori promote $\mathrm{B} 7-\mathrm{H} 1$ expression by suppressing miR-152 and miR-200b in gastric cancer cells. PloS one. 2017;12(1):e0168822

179. Kao SC, Cheng YY, Williams M, Kirschner MB, Madore J, Lum $\mathrm{T}$ et al (2017) Tumor suppressor microRNAs contribute to the regulation of PD-L1 expression in malignant pleural mesothelioma. J Thorac Oncol 12(9):1421-1433

180. Jia L, Xi Q, Wang H, Zhang Z, Liu H, Cheng Y et al (2017) miR-142-5p regulates tumor cell PD-L1 expression and enhances anti-tumor immunity. Biochem Biophys Res Commun 488(2):425-431

181. Fujita Y, Yagishita S, Hagiwara K, Yoshioka Y, Kosaka N, Takeshita F et al (2015) The clinical relevance of the miR-197/ CKS1B/STAT3-mediated PD-L1 network in chemoresistant nonsmall-cell lung cancer. Mol Ther 23(4):717-727

182. Zhu J, Chen L, Zou L, Yang P, Wu R, Mao Y et al (2014) MiR20b, -21, and -130b inhibit PTEN expression resulting in B7-H1 over-expression in advanced colorectal cancer. Hum Immunol 75(4):348-353

183. Terawaki S, Chikuma S, Shibayama S, Hayashi T, Yoshid T, Okazaki $\mathrm{T}$ et al (2011) IFN- $\alpha$ directly promotes programmed cell death-1 transcription and limits the duration of T cell-mediated immunity. J Immunol (Baltimore, Md : 1950) 186(5):2772-9

184. Cho H-Y, Lee S-W, Seo S-K, Choi I-W, Choi I, Lee S-W (2008) Interferon-sensitive response element (ISRE) is mainly responsible for IFN-alpha-induced upregulation of programmed death-1 (PD-1) in macrophages. Biochem Biophys Acta 1779(12):811-819

185. Austin JW, Lu P, Majumder P, Ahmed R, Boss JM (2014) STAT3, STAT4, NFATc1, and CTCF regulate PD-1 through multiple novel regulatory regions in murine T cells. J Immunol (Baltimore, Md : 1950) 192(10):4876-86

186. Quatrini L, Vacca P, Tumino N, Besi F, Di Pace AL, Scordamaglia F, et al. Glucocorticoids and the cytokines IL-12, IL-15 and IL-18 present in the tumor microenvironment induce PD-1 expression on human Natural Killer cells. J Allergy Clin Immunol. 2020.

187. Bally APR, Lu P, Tang Y, Austin JW, Scharer CD, Ahmed R et al (2015) NF- $\kappa B$ regulates PD-1 expression in macrophages. J Immunol (Baltimore, Md : 1950) 194(9):4545-54

188. Oestreich KJ, Yoon H, Ahmed R, Boss JM (2008) NFATc1 regulates PD-1 expression upon T cell activation. J Immunol (Baltimore, Md : 1950) 181(7):4832-9

189. Macián F, López-Rodríguez C, Rao A (2001) Partners in transcription: NFAT and AP-1. Oncogene 20(19):2476-2489

190. Staron MM, Gray SM, Marshall HD, Parish IA, Chen JH, Perry CJ et al (2014) The transcription factor FoxO1 sustains expression of the inhibitory receptor PD-1 and survival of antiviral CD8(+) T cells during chronic infection. Immunity 41(5):802-814

191. Lu P, Youngblood BA, Austin JW, Mohammed AUR, Butler R, Ahmed R et al (2014) Blimp-1 represses CD8 T cell expression of PD-1 using a feed-forward transcriptional circuit during acute viral infection. J Exp Med 211(3):515-527

192. Kao C, Oestreich KJ, Paley MA, Crawford A, Angelosanto JM, Ali MA et al (2011) Transcription factor T-bet represses expression of the inhibitory receptor PD-1 and sustains virus-specific $\mathrm{CD} 8+\mathrm{T}$ cell responses during chronic infection. Nat Immunol 12(7):663-71

193. Xie MM, Koh B-H, Hollister K, Wu H, Sun J, Kaplan MH et al (2017) Bcl6 promotes follicular helper T-cell differentiation and PD-1 expression in a Blimp1-independent manner in mice. Eur J Immunol 47(7):1136-1141

194. Youngblood B, Oestreich KJ, Ha S-J, Duraiswamy J, Akondy RS, West EE et al (2011) Chronic virus infection enforces demethylation of the locus that encodes PD-1 in antigen-specific CD8(+) T cells. Immunity $35(3): 400-412$

195. Li Q, Johnston N, Zheng X, Wang H, Zhang X, Gao D et al (2016) miR-28 modulates exhaustive differentiation of T cells through silencing programmed cell death-1 and regulating cytokine secretion. Oncotarget 7(33):53735-53750

196. Wei J, Nduom EK, Kong L-Y, Hashimoto Y, Xu S, Gabrusiewicz $\mathrm{K}$ et al (2016) MiR-138 exerts anti-glioma efficacy by targeting immune checkpoints. Neuro Oncol 18(5):639-648

197. Magnus T, Schreiner B, Korn T, Jack C, Guo H, Antel J et al (2005) Microglial expression of the B7 family member B7 homolog 1 confers strong immune inhibition: implications for immune responses and autoimmunity in the CNS. The Journal of neuroscience : the official journal of the Society for Neuroscience 25(10):2537-2546

198. Watanabe R, Hilhorst M, Zhang H, Zeisbrich M, Berry GJ, Wallis $\mathrm{BB}$, et al. Glucose metabolism controls disease-specific signatures of macrophage effector functions. JCI insight. 2018;3(20).

199. Chen G, Kim YH, Li H, Luo H, Liu D-L, Zhang Z-J et al (2017) PD-L1 inhibits acute and chronic pain by suppressing nociceptive neuron activity via PD-1. Nat Neurosci 20(7):917-926

200. Karl F, Colaço MBN, Schulte A, Sommer C, Üçeyler N (2019) Affective and cognitive behavior is not altered by chronic constriction injury in B7-H1 deficient and wildtype mice. BMC Neurosci 20(1):16

201. Ramos-Casals M, Brahmer JR, Callahan MK, Flores-Chávez A, Keegan N, Khamashta MA et al (2020) Immune-related adverse events of checkpoint inhibitors. Nat Rev Dis Primers 6(1):38

Publisher's Note Springer Nature remains neutral with regard to jurisdictional claims in published maps and institutional affiliations. 